\title{
1994 Washington State Directory of Biomass Energy Facilities
}
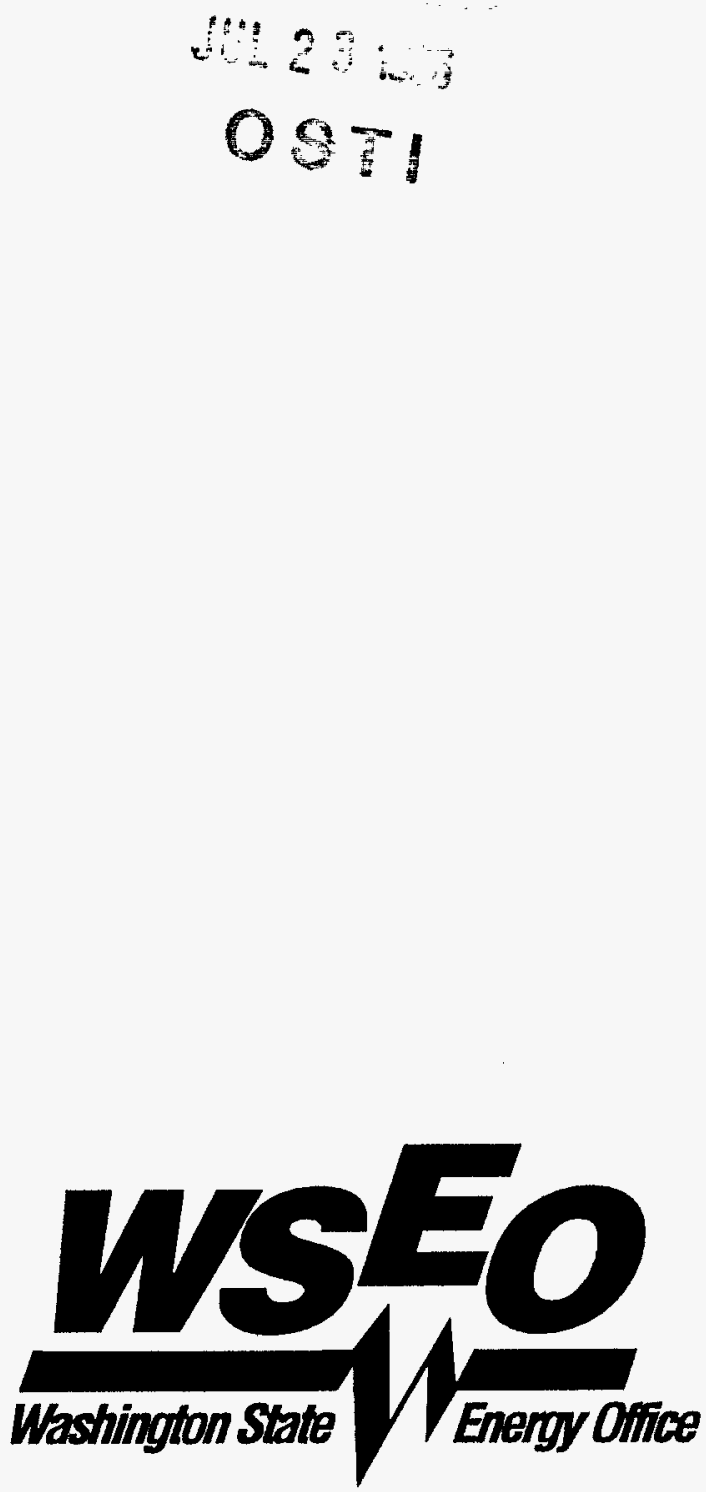


\title{
1994 Washington State Directory of Biomass Energy Facilities
}

Prepared by.

Joyce A. Deshaye

Bioenergy Specialist

(206) $956-2032$

James D. Kerstetter, Ph.D. Bioenergy Program Manager

(206) 956-2069

\section{DISCLAIMER}

\begin{abstract}
This report was prepared as an account of work sponsored by an agency of the United States Government. Neither the United States Government nor any agency thereof, nor any of their employees, makes any warranty, express or implied, or assumes any legal liability or responsibility for the accuracy, completeness, or usefulness of any information, apparatus, product, or process disclosed, or represents that its use would not infringe privately owned rights. Reference herein to any specific commercial product, process, or service by trade name, trademark, manufacturer, or otherwise does not necessarily constitute or imply its endorsement, recommendation, or favoring by the United States Government or any agency thereof. The views and opinions of authors expressed herein do not necessarily state or reflect those of the United States Government or any agency thereof.
\end{abstract}

March 1994

WSEO \#94-068

Replaces WSEO \#92-088 \&

WAOENG 90-70.

Printed on recycled paper
Washington State Energy Office

925 Plum St SE

P.O. Box 43165

Olympia, WA 98504-3165

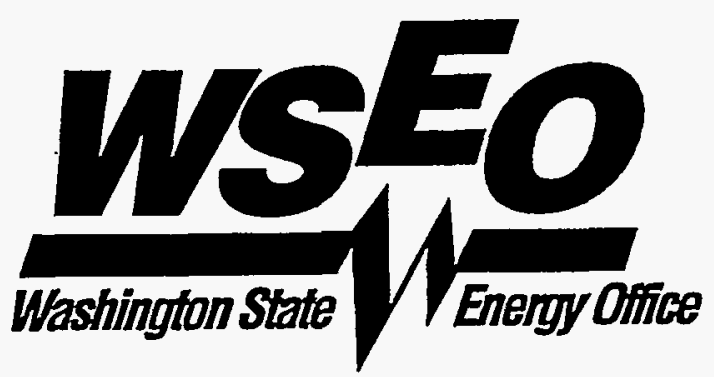


This document will be made availáble through the National Technical Information Service. 


\section{DISCLAIMER}

Portions of this document may be illegible in electronic image products. Images are produced from the best available original document. 


\section{Acknowledgments}

The authors wish to thank the U.S. Department of Energy and the Bonneville Power Administration for their financial contribution to this effort. Special thanks are due to the facility managers that took the time to respond to the survey. Without their cooperation, this report could not have been completed.

\section{Disclaimer}

This report was prepared by the Washington State Energy Office (WSEO) as an account of work sponsored by the U.S. Department of Energy. Neither the United States, the state of Washington, the Washington State Energy Office, nor any of their employees, nor their contractors, subcontractors, nor their employees, make any warranty, expressed or implied, or assumes legal responsibility for the accuracy, completeness, or the usefulness of any information, apparatus, product, or process disclosed within this report.

\section{American Disabilities Act}

To obtain additional copies of this report or to receive the report in alternate format (large print, Braille, or audio tape), contact:

The Washington State Energy Office

925 Plum Street SE/Town Square Building \#4

P.O. Box 43165

Olympia, WA 98504-3165

(206) $956-2000$

TDD (206) 956-2218 


\section{Introduction}

This is the fourth edition of the Washington Directory of Biomass Energy Facilities, the first edition was published in 1987. The purpose of this directory is to provide a listing of and basic information about known biomass producers and users within the state to help demonstrate the importance of biomass energy in fueling our state's energy needs. In 1992 (latest statistical year), estimates show that the industrial sector in Washington consumed nearly 128 trillion Btu of electricity, nearly 49.5 trillion Btu of petroleum, over 82.2 trillion Btu of natural gas, and over 4.2 trillion Btu of coal. Facilities listed in this directory generated approximately 114 trillion Btu of biomass energy -- 93 trillion were consumed from waste wood and spent chemicals. In the total industrial energy picture, wood residues and chemical cooking liquors placed second only to electricity.

This directory is divided into four main sections biogas production, biomass combustion, ethanol production, and solid fuel processing facilities. Each section contains maps and tables summarizing the information for each type of biomass. Provided in the back of the directory for reference are a conversion table, a table of abbreviations, a glossary, and an index.

Chapter 1 deals with biogas production from both landfills and sewage treatment plants in the state. Biogas produced from garbage and sewage can be scrubbed and used to generate electricity. At the present time, biogas collected at landfills is being flared on-site, however four landfills are investigating the feasibility of gas recovery for energy. Landfill biogas accounted for approximately 6 percent of the total biomass reported. Sewage treatment biogas accounted for 0.6 percent. Biogas generated from sewage treatment plants is primarily used for space and process heat, only one facility presently scrubs and sells methane. Together, landfill and sewage treatment plant biogas represented over 6.6 percent of the total biomass reported.

Chapter 2 provides information on biomass combustion facilities in the state. It is divided into chemical recovery, municipal solid waste and wood combustion facilities.

Wood combustion facilities use hog fuel (waste wood such as sawdust, planner shavings, bark, stumps, brush, left over wood chunks, wood pellets, clean urban wood waste, etc.) to generate power for their industrial needs. Much of hog fuel is generated by lumber mills and pulp and paper mills as a result of the manufacturing processes, some is generated from waste wood processors and purchased. Wood combustion facilities generated the greatest amount of energy, accounting for 51 percent of the total biomass reported.

Spent chemicals (cooking liquors) and lignins have high Btu value and are generated as a by-product of the pulp and paper mills. They are recovered from the digesters in the pulp making process and burned in recovery furnaces to produce steam. Their reuse helps to maintain environmental cleanliness. They are the second largest source of biomass energy reported in this directory, accounting for 31 percent of the total.

As landfill seepage threatens our water supply and pollutes our soils, municipal solid waste combustion is becoming a more environmentally appropriate way to deal with trash that is not recycled. Waste-to-energy plants reduce the amount of garbage sent to landfills and generate electricity to supply thousands of homes. Energy supplied from municipal solid waste combustion accounted for 4 percent of the total reported. 
The third Chapter focuses on ethanol production. Ethanol fuels have been used as fuel extenders for the past ten years. Since the fall of 1992, ethanol has. been used as a fuel additive to help reduce carbon monoxide emissions from motor vehicles. Ethanol accounts for .6 percent of biomass resources reported in this directory.

Listed in Chapter 4 are solid fuel processing facilities. We have included two categories, waste wood processors and wood pellet processors. The majority of this waste wood comes from clean construction debris and land clearing from construction sites. It is processed into hog fuel and includes stumps, bark, etc. Waste wood processing accounted for 6 percent of the total reported. Wood pellets are generated primarily from waste generated from sawmills. They accounted for nearly 1.5 percent of the total reported.

\section{Summary}

In 1992, Washington's industrial sector consumed nearly 357 trillion Btu (British thermal units) of energy, of that, nearly 128 trillion Btu were from electricity; close to 136 trillion Btu was from fossil fuel -- natural gas, petroleum, and coal; and 93 trillion was from biomass (wood residues and recovered chemical cooking liquors). Biomass supplied close to 41 percent of the industrial fuel used in Washington State. Table 1 shows the gross energy equivalent of the average plant output for facilities listed in this directory -- together they produced approximately 114 trillion Btu. The greatest portion produced and used by industry was from wood residues and chemical recovery (93 trillion Btu). Table 2, shows the megawatt capacity and average megawatt output of biomass energy facilities. When combined, biomass facilities have capacity to supply over 309 megawatts of electricity and are generating over 241 average megawatts from biomass -- that is a sizable contribution towards meeting our state's energy needs.

Table 1

Washington State Biomass Energy Production Comparison for 1987, 1989, 1991, and 1993

\begin{tabular}{|c|c|c|c|c|c|}
\hline Type of Biomass & $\begin{array}{c}1987 \\
\text { Billion } \\
\text { Btu }\end{array}$ & $\begin{array}{c}1989 \\
\text { Billion } \\
\text { Btu }\end{array}$ & $\begin{array}{c}1991 \\
\text { Billion } \\
\text { Btu }\end{array}$ & $\begin{array}{c}1993 \\
\text { Billion } \\
\text { Btu }\end{array}$ & $\begin{array}{c}\text { Percent } \\
\text { of Total } \\
1993 \\
\end{array}$ \\
\hline Ethanol Production & 600 & 798 & 939 & 672 & $0.6 \%$ \\
\hline Landfill Biogas Production & NA & NA & 5,071 & 6,488 & $6 \%$ \\
\hline Municipal Solid Waste Combustion & 300 & 1,845 & 4,624 & 4,285 & $4 \%$ \\
\hline Sewage Treatment Biogas Production & 600 & 810 & 648 & 701 & $0.6 \%$ \\
\hline Spent Chemical Cooking Liquors & NA & NA & 34,506 & 35,148 & $31 \%$ \\
\hline Waste Wood Combustion & 57,496 & 58,834 & 58,935 & 58,218 & $51 \%$ \\
\hline Waste Wood Processing & NA & NA & 7,326 & 7,148 & $6 \%$ \\
\hline Wood Pellet Processing & $<1$ & 2,321 & 2,510 & $1 ; 735$ & $1.5 \%$ \\
\hline Total & 58,996 & 64,608 & 114,559 & 114,395 & \\
\hline
\end{tabular}


Table 2

1993 Electric Capacity and Average Output of Biomass Energy Facilities

\begin{tabular}{|c|c|c|}
\hline Type of Biomass & $\begin{array}{c}\text { Megawatt } \\
\text { Capacity }\end{array}$ & $\begin{array}{l}\text { Average Megawatt } \\
\text { Output }\end{array}$ \\
\hline $\begin{array}{l}\text { Municipal Solid Waste Combustion } \\
\text { Recomp of Washington } \\
\text { Skagit County Resource Recovery } \\
\text { Spokane Trash-to-Energy } \\
\text { Tacoma Steam Plant,No. } 2^{*} \\
\text { Sub Total }\end{array}$ & $\begin{array}{r}2.0 \\
2.5 \\
26.0 \\
43.0 \\
73.5\end{array}$ & $\begin{array}{r}2.0 \\
2.5 \\
26.0 \\
29.0 \\
59.5\end{array}$ \\
\hline $\begin{array}{l}\text { Waste Wood Combustion } \\
\text { Longview Fibre Co. } \\
\text { Omak Wood Products } \\
\text { Port Townsend Paper } \\
\text { Rayonier, Inc. } \\
\text { Vaagen Brothers -- Colville } \\
\text { Weyerhaeuser Co. -- Cosmopolis } \\
\text { Weyerhaeuser Co. -- Longview } \\
\text { Washington Water Power Company } \\
\text { Sub Total }\end{array}$ & $\begin{array}{r}30.0 \\
7.5 \\
18.5 \\
12.0 \\
4.0 \\
15.0 \\
30.0 \\
48.0 \\
165.0\end{array}$ & $\begin{array}{r}13.0 \\
7.5 \\
6.1 \\
1.6 \\
4.0 \\
11.0 \\
30.0 \\
50.3 \\
123.5\end{array}$ \\
\hline $\begin{array}{l}\text { Sewage Treatment Plants } \\
\text { Metro West Point } \\
\text { Spokane } \\
\text { Sub Total }\end{array}$ & $\begin{array}{r}1.3 \\
.3 \\
1.6\end{array}$ & $\begin{array}{r}1.1 \\
.3 \\
1.4\end{array}$ \\
\hline $\begin{array}{l}\text { Spent Chemical Cooking Liquors } \\
\text { Longview Fibre Co. } \\
\text { Weyerhaeuser Paper Co. -- Longview } \\
\text { Sub Total }\end{array}$ & $\begin{array}{r}60.0 \\
8.9 \\
68.9\end{array}$ & $\begin{array}{r}48.0 \\
8.9 \\
56.9\end{array}$ \\
\hline Grand Total & 309 & 241.3 \\
\hline
\end{tabular}

*Facility uses a combination of refuse derived fuel, hog fuel and coal to generate electricity.

Figure 1 shows the names of counties in the state of Washington. Please refer to this map when necessary for the location of counties. 


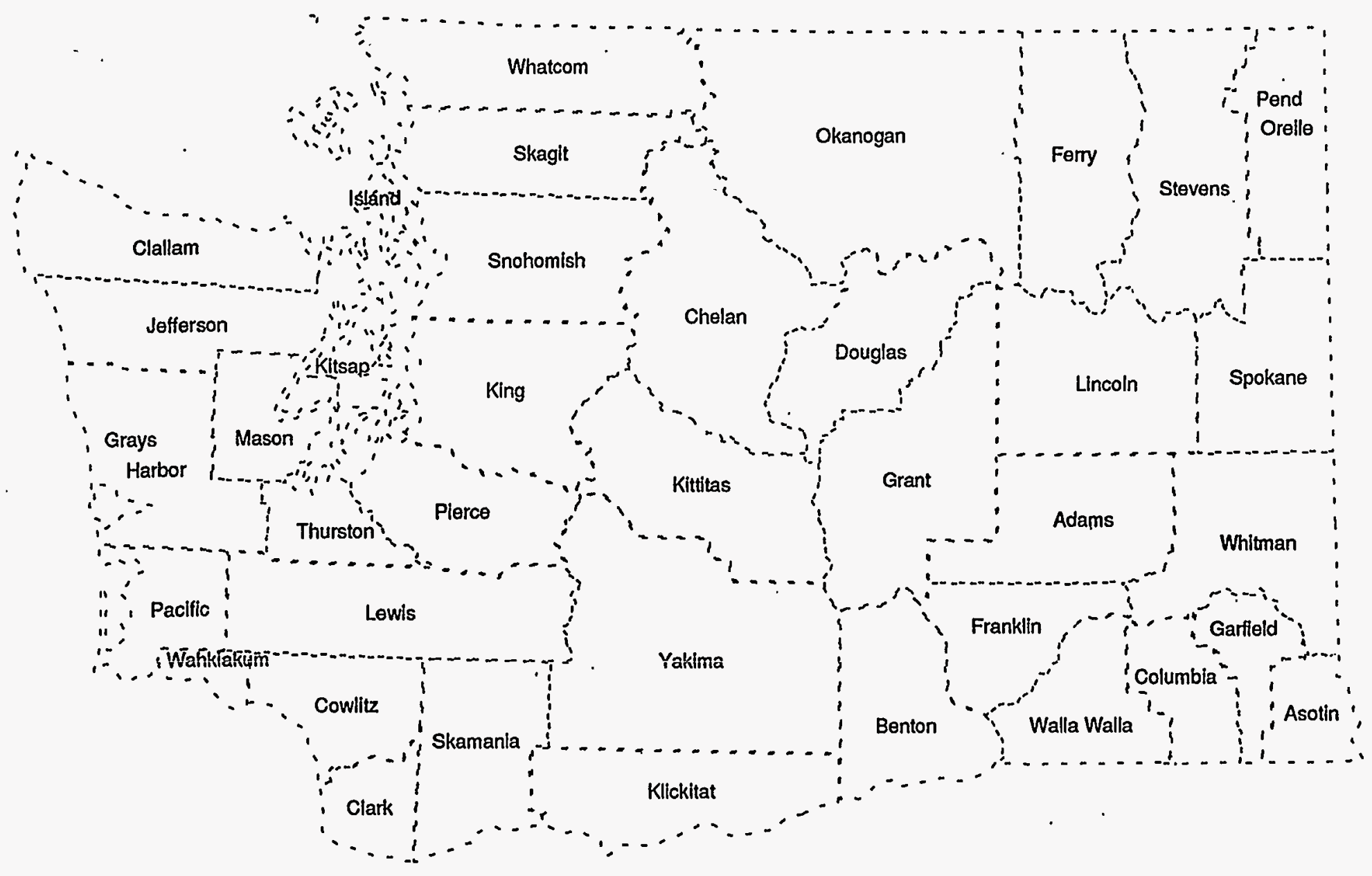

Figure 1

Washington State Counties 


\section{Contents}

Introduction

\section{Chapter 1 Biogas Production}

Landfills $\quad 1$

Landfills

Listing Changes From 1992 Edition : 8

Sewage Treatment Plants $\quad:-9$

Sewage Treatment Plants $\quad 12$

Listing Changes From 1992 Edition 19

\section{Chapter 2 Biomass Combustion}

Chemical Recovery $\quad 21$

Chemical Recovery Facilities $\quad$. 24

Listing Changes From 1992 Edition $\quad 25$

Municipal Solid Waste $\quad 27$

Municipal Solid Waste Combustion Facilities $\quad 30$

Listing Changes From 1992 Edition 31

Waste Wood Combustion 33

Forest Products Industry Facilities $\quad 37$

Other Facilities $\quad 54$

Listing Changes From 1992 Edition 56

Chapter 3 Ethanol Production

Ethanol

Ethanol Production Facilities

60

Listing Changes From 1992 Edition

62 
Chapter 4 Solid Fuel Processing

Waste Wood . 63

Waste Wood Processing Facilities $\quad 66$

Listing Changes From 1992 Edition $\quad 68$

Wood Pellets $\quad 69$

Wood Pellet Processing Facilities $\quad \mathbf{7 2}$

Listing Changes From 1992 Edition $\quad 74$

$\begin{array}{ll}\text { Conversion Table } & 75\end{array}$

Table of Abbreviations $\quad 77$

Glossary $\quad 79$

Index $\quad 83$ 


\section{Maps}

Figure 1 - Washington State Counties iv

Figure 2 - 1993 Landfill Biogas Production 2

Figure 3 - 1993 Sewage Treatment Biogas Production 10

Figure 4 - 1993 Chemical Recovery 22

Figure 5 - 1993 Municipal Solid Waste Combustion 28

Figure 6 - 1993 Waste Wood Combustion . 34

- Figure 7 - 1993 Ethanol Production 5

Figure 8 - 1993 Waste Wood Processing 64

Figure 9 - 1993 Wood Pellet Processing $\quad \mathbf{7 0}$.

\section{List of Tables}

Table 1 - Washington State Biomass Energy Production . Comparison Table for 1987, 1989, 1991, and 1993.

Table 2 - 1993 Electric Capacity and Average Output of Biomass Energy Facilities

Table 3 - 1993 Landfill Biogas Production 2

Table 4 - 1993 Sewage Treatment Biogas Production 10

Table 5 - 1993 Chemical Recovery 20

Table 6 - 1993 Municipal Solid Waste Combustion 26

Table 7 - 1993 Wood Combustion 32

Table 8 - 1993 Ethanol Production 56.

Table 9 - 1993 Waste Wood Processing 62.

Table 10 - 1993 Wood Pellet Processing 68 


\title{
Chapter 1
}

\section{Biogas Production}

\author{
Landfills \\ Sewage Treatment
}




\section{Landfills}




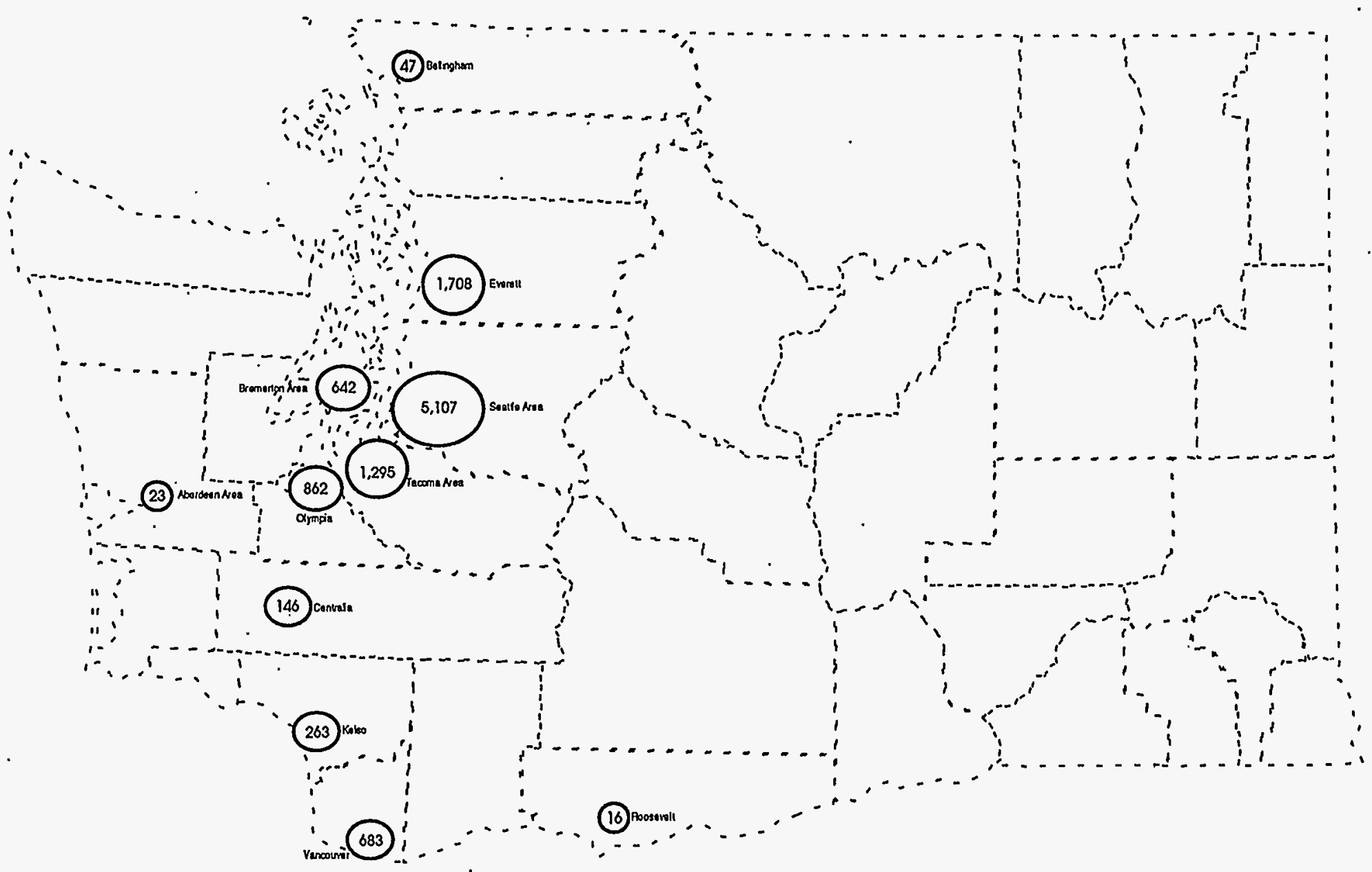

Biogas - standard cubic feet/year (millions)

\section{Figure 2}

1993 Washington State Landfill Biogas Output

Source: WSEO, 1994 Washington State Directory of Biomass Energy Facilities 
Table 3

1993 Washington State Landfill Biogas Production

Sorted by Estimated Volume of Biogas

\begin{tabular}{|c|c|c|c|c|}
\hline Landfill & County & $\begin{array}{c}\text { Estimated } \\
\text { Vol. of Biogas } \\
\text { (million cubic } \\
\text { feet/year) }\end{array}$ & $\begin{array}{l}\text { Gross Energy } \\
\text { Equivalent }^{1} \\
\text { (million }^{\text {Btu/year) }}\end{array}$ & End Use \\
\hline $\begin{array}{l}\text { Cedar Hills } \\
\text { Cathcart } \\
\text { Tacoma } \\
\text { Kent Highlands } \\
\text { Hawks Prairie } \\
\text { Leichener } \\
\text { Olympic View } \\
\text { Midway } \\
\text { Cowlitz County } \\
\text { Centralia } \\
\text { Hansville } \\
\text { Hobart } \\
\text { Cedarville } \\
\text { Aberdeen } \\
\text { Mason County } \\
\text { Hidden Valley } \\
\text { Roosevelt Regional } \\
\text { Purdy } \\
\text { Hoquim } \\
\text { Enumclaw }\end{array}$ & $\begin{array}{l}\text { King } \\
\text { Snohomish } \\
\text { Pierce } \\
\text { King } \\
\text { Thurston } \\
\text { Clark } \\
\text { Kitsap } \\
\text { King } \\
\text { Cowlitz } \\
\text { Lewis } \\
\text { Kitsap } \\
\text { King } \\
\text { Whatcom } \\
\text { Grays Harbor } \\
\text { Mason } \\
\text { Pierce } \\
\text { Klickitat } \\
\text { Pierce } \\
\text { Grays Harbor } \\
\text { King } \\
\end{array}$ & $\begin{array}{r}3,784 \\
1,708 \\
1,261 \\
867 \\
862 \\
683 \\
526 \\
372 \\
263 \\
146 \\
116 \\
84 \\
47 \\
23^{4} \\
21^{2} \\
18 \\
16^{3} \\
16 \\
\mathrm{NA} \\
\mathrm{NA} \\
\end{array}$ & $\begin{array}{r}2,270,400 \\
1,024,800 \\
756,600 \\
520,744 \\
517,200 \\
409,800 \\
315,600 \\
223,200 \\
157,800 \\
87,600 \\
69,379 \\
50,458 \\
28,200 \\
13,786 \\
12,384 \\
11,038 \\
9,600 \\
9,461 \\
\text { NA } \\
\text { NA }\end{array}$ & $\begin{array}{l}\text { Flared, investigating gas recovery } \\
\text { Flared } \\
\text { Flared, investigating gas recovery } \\
\text { Flared, investigating gas recovery } \\
\text { Flared } \\
\text { Flared } \\
\text { Flared } \\
\text { Flared } \\
\text { Flared } \\
\text { Flared } \\
\text { Flared } \\
\text { Flared } \\
\text { Flared, investigating gas recovery } \\
\text { Flared } \\
\text { Flared } \\
\text { Flared } \\
\text { Flared } \\
\text { Flared } \\
\text { Flared } \\
\text { Flared } \\
\end{array}$ \\
\hline Total & & 10,813 & $6,488,050$ & \\
\hline
\end{tabular}

1 Energy Equivalent based of 600 Btu per standard cubic foot of Landfill Gas

2 Where in place tonnage was not given, WSEO estimated Depth (feet) $x$ area (acres) $\times 645$ tons per acre $=$ tons of waste, the tons of waste was then multiplied by $80 \mathrm{scf} / \mathrm{ton}$ (low case annual LFG production)

3 Where in place tonnage was given, WSEO estimated $80 \mathrm{scf} /$ ton (low case annual LFG production)

4800 pounds per cubic yard of refuse 


\section{Landfills}

Aberdeen Landfill

4201 Olympic Hwy. E.

Aberdeen, WA 98520

Phone: (206) 533-1251

Contact Person: Delroy Cox

Start of operation: 1968

Closure date: 1993

Area (total acres): 27

Acres banked:

In place tonnage: 718 thousand cubic yards

Average depth (feet): 55

Annual waste vol. (tons):

Vol. of gas flared (scf/min.): Unkown

Vol. of gas used to gen. electricity on-site: None

Vol. of gas scrubbed \& sold to gas utility: None

Cathcart Landfill

Public Works, Solid Waste Div.

2930 Wetmore Ave.

Everett, WA 98201

Phone: (206) 388-6495

Contact Person: Ken Moser

Start of operation: 1980, flare 1989

Closure date: 1992

Area (total acres): 200 acres

Acres banked: 56

In place tonnage: $3,258,989$

Average depth (feet): 110

Annual waste vol. (tons): None

Vol. of gas flared (scf/min.): 3,250

Vol. of gas used to gen. electricity on-site: None

Vol. of gas scrubbed \& sold to gas utility: None

\section{Cedar Hills}

King County Solid Waste Div.

400 Yesler Way, Room 600

Seattle, WA 98104

Phone: (206) 296-4437 .

Contact Person: Ed Henderson

Start of operation: 1964

Closure date: 2022

(continued on next column)
Area (total acres): 900

Acres banked: 200

In place tonnage: 20.031 million tons

Average depth (feet): 150

Annual waste vol. (tons): $900,000+/-$

Vol. of gas flared ( $\mathrm{sc \textrm {f }} / \mathrm{min}$.): 7,200

Vol. of gas used to gen. electricity on-site: None

Vol. of gas scrubbed \& sold to gas utility: None -

* Note: Investigating gas recovery

Cedarville Landfill

Whatcom Co. Solid Waste Division

5256 NW Drive

Bellingham, WA 98226

Phone: (206) 676-7695

Contact Person: Bob Jurica

Start of operation: 1981

Closure date: 1990

Area (total acres): 9

Acres banked:

In place tonnage: $250 ; 000$ tons

Average depth (feet): 50

Annual waste vol. (tons):

Vol. of gas flared (scf/min.): $80-100$.

Vol. of gas used to gen. electricity on-site: None

Vol. of gas scrubbed \& sold to gas utility: None

*Note: Investigating gas recovery

\section{Centralia Landfill}

P.O. Box 609

Centralia, WA 98531

Phone: (206) 736-1954

Contact Person: Lee First

Start of operation: 1958, flare fall ' 90

Closure date: 1993, 4/94 summer cap

Area (total acres): 80

Acres banked:

In place tonnage:

Average depth (feet): 25

Annual waste vol. (tons):

Vol. of gas flared (scf/min.): 278 avg @ 45\% methane

Vol. of gas used to gen. electricity on-site: None

Vol. of gas scrubbed \& sold to gas utility: None 


\section{Cowlitz County Landfill}

Public Works Department

207 4th Ave. N.

Kelso, WA 98626

Phone: (206) 577-3125

Contact Person: Don Olson

Start of operation: 1975

Closure date: 1992 (site "A" closed,

site " $B$ " continues to operate)

Area (total acres): 50

Acres banked: 35 acres

In place tonnage: 950 thousand tons

Average depth (feet): 25

Annual waste vol. (tons): N/A for site "A"

Vol. of gas flared (scf/min.): 500 at 55\% methane

Vol. of gas used to gen. electricity on-site: None

Vol. of gas scrubbed \& sold to gas utility: None

\section{Enumclaw Landfill}

King County Solid Waste Div.

400 Yesler Way, Room 600

Seattle, WA 98104

Phone: (206) 296-4437

Contact Person: Ed Henderson

Start of operation: 1958

Closure date: 1993

Area (total acres): 25

Acres banked:

In place tonnage: Unkown

Average depth (feet): 50

Annual waste vol. (tons):

Vol. of gas flared (scf/min.): $750 @ 8 \mathrm{hrs} /$ day

$39 \%$ methane

Vol. of gas used to gen. electricity on-site: None

Vol. of gas scrubbed \& sold to gas utility: None

\section{Hansville Landfill}

614 Division Street

Port Orchard, WA 98366

Phone: (206) 876-7121

Contact Person: Paul Dour

Start of operation: 1962

Closure date: 1989

Area (total acres): 60

Acres banked:
In place tonnage: 1 million cubic yards

Average depth (feet): 40

Annual waste vol. (tons): .

Vol. of gas flared (scf/min.): 220

Vol. of gas used to gen. electricity on-site: None

Vol. of gas scrubbed \& sold to gas utility: None

\section{Hawks Prairie Landfill \\ Dept of Public Works \\ 2000 Lakeridge Dr. SW \\ Olympia, WA 98502 \\ Phone: (206) 786-5136 \\ Contact Person: Jeff Stèrnhagen}

Start of operation:

Closure date: 1997

Area (total acres): 110

Acres banked: Closed/unlined areas 50 acres, active area 15 acres, future/reserve 20 acres,

buffer areas 25 acres

In place tonnage:

Average depth (feet): 60

Annual waste vol. (tons): 117,879

Vol. of gas flared (scf/min.): 1,640

Vol. of gas used to gen. electricity on-site: None

Vol. of gas scrubbed \& sold to gas utility: None

Note: Feasibility of energy recovery being investigated in 1994.

\section{Hidden Valley Landfill}

P.O. Box 73057

17925 Meridian St. E.

Puyallup, WA 98373

Phone: (206) 847-7555

Contact Person: Jim Crandall

Start of operation: 1959

Closure date: March 1996 (approximately)

Area (total acres): 72

Acres banked: 65

In place tonnage: Unkown

Average depth (feet): 110

Annual waste vol. (tons): 430,000 (approximately)

Vol. of gas flared (scf/min.): 35

Vol. of gas used to gen. electricity on-site: None

Vol. of gas scrubbed \& sold to gas utility: None

(continued on next column) 


\section{Hobart Landfill}

King County Solid Waste Div.

400 Yesler Way, Room 600

Seattle, W.A 98104

Phone: (206) 296-4422

Contact Person: Victor O. Okereke

Start of operation: 1958

Closure date: 1994

Area (total acres): 35

Acres banked: 15 acres (area w/final cover)

In place tonnage: Not available

Average depth (feet): 60

Annual waste vol. (tons):

Vol. of gas flared (scf/min.): 160 currently, 500 in ' 94

Vol. of gas used to gen. electricity on-site: None

Vol. of gas scrubbed \& sold to gas utility: None

\section{Hoquiam Landfill}

609 8th Street

Hoquiam, WA 98550

Phone: (206) 532-5700

Contact Person: Fran Eide

Start of operation: 1976

Closure date: 1990

Area (total acres): 50

Acres banked:

In place tonnage: Unknown

Average depth (feet):

Annual waste vol. (tons): None

Vol. of gas flared (scf/min.): Unknown

Vol. of gas used to gen. electricity on-site: None

Vol. of gas scrubbed \& sold to gas utility: None

\section{Kent Highlands}

505 Dexter Horton Bldg.

710 Second Avenue

Seattle, WA 98104-1713

Phone: (206) 684-7686

Contact Person: Martha Burke

Start of operation: 1968

Closure date: 1986

(continued on next column)
Area (total acres): 100

Acres banked: 60

In place tonnage: 5 million tons

Average depth (feet): 95

Annual waste vol. (tons):

Vol. of gas flared (scf/min.): 1,650

Vol. of gas used to gen. electricity on-site: None

Vol. of gas scrubbed \& sold to gas utility: None

*Note: Investigating gas recovery

\section{Leichner Landfill}

9411 NE 94th

Vancouver, WA 98662

Phone: (206) 892-5370

Contact Person: Jay McCuistion

Start of operation: 1939

Closure date: 1991

Area (total acres): 80

- Acres banked: 80 acres

In place tonnage: 5.75 million tons

Average depth (feet): 38

Annual waste vol. (tons):

Vol. of gas flared (scf/min.): 1,300

Vol. of gas used to gen. electricity on-site: None

Vol. of gas scrubbed \& sold to gas utility: None

\section{Mason County Landfill}

Dept. of Community Development

P.O. Box 578

Shelton, WA 98584

Phone: (206) 427-5271

Contact Person: Paul Johnston

Start of operation: 1971

Closure date: 1993

Area (total acres): 8

Acres banked:

In place tonnage: Unkown

Average depth (feet): 50

Annual waste vol. (tons):

Vol. of gas flared (scf/min.): Unknown

Vol. of gas used to gen. electricity on-site: None

- Vol. of gas scrubbed \& sold to gas utility: None 
Midway Landfill

505 Dexter Horton Bldg.

710 Second Avenue

Seattle, WA 98104-1713

Phone: (206) 684-7693

Contact Person: Jeff Neuner

Start of operation: 1966

Closure date: 1983 waste - 1991 construction

Area (total acres): 60

Acres banked: 40

In place tonnage: 3 million tons

Average depth (feet): 115

Annual waste vol. (tons):

Vol. of gas flared (scf/min.): 707

Vol. of gas used to gen. electricity on-site: None

Vol. of gas scrubbed \& sold to gas utility: None

\section{Olympic View Sanitary Landfill \\ 512 Sheldon Blvd. \\ Bremerton, WA 98310 \\ Phone: (206) 674-2331 \\ Contact Person: Lee Wilson}

Start of operation: 1960

Closure date: 2004

Area (total acres): 250

Acres banked: 65

In place tonnage: Unknown

Average depth (feet): 100

Annual waste vol. (tons): 200,000

Vol. of gas flared (scf/min.): 1,000

Vol. of gas used to gen. electricity on-site: None

Vol. of gas scrubbed \& sold to gas utility: None

\section{Purdy Landfill}

P.O. Box 73057

17925 Meridian St. E.

Puyallup, WA 98373

Phone: (206) 847-7555

Contact Person: Jim Crandall

Start of operation: 1956

Closure date: 1990

(continued on next column)
Area (total acres): 24

Acres banked: 11

In place tonnage: Unknown

Average depth (feet): 80

Annual waste vol. (tons):

Vol. of gas flared (scf/min.): 30

Vol. of gas used to gen. electricity on-site: None

Vol. of gas scrubbed \& sold to gas utility: None

\section{Roosevelt Regional Landfill}

P.O. Box 358

Roosevelt, WA 99356

Phone: (509) 374-5641

Contact Person: Rick Morck

Start of operation: 1990

Closure date: 2030

Area (total acres): 915

Acres banked: 72

In place tonnage: 200 thousand tons

Average depth (feet): 180

Annual waste vol. (tons): 1.5 million

Vol. of gas flared (scf/min.): None

Vol. of gas used to gen. electricity on-site: None

Vol. of gas scrubbed \& sold to gas utility: None

\section{Tacoma Landfill}

3510 S. Mullen

Tacoma, WA 98409

Phone: (206) 591-5543

Contact Person: Walt Forslund

Start of operation: 1960

Closure date: 2014

Area (total acres): 240

Acres banked: 130

In place tonnage: 5 million

Average depth (feet): 50

Annual waste vol. (tons): 55,300

Vol. of gas flared (scf/min.): 2,400 @ $41 \%$ methane

Vol. of gas used to gen. electricity on-site: None

Vol. of gas scrubbed \& sold to gas utility: None 


\section{Landfill Biogas Production Listing Changes from 1992 Edition}

No new facilities added or deleted. 


\section{Sewage Treatment}




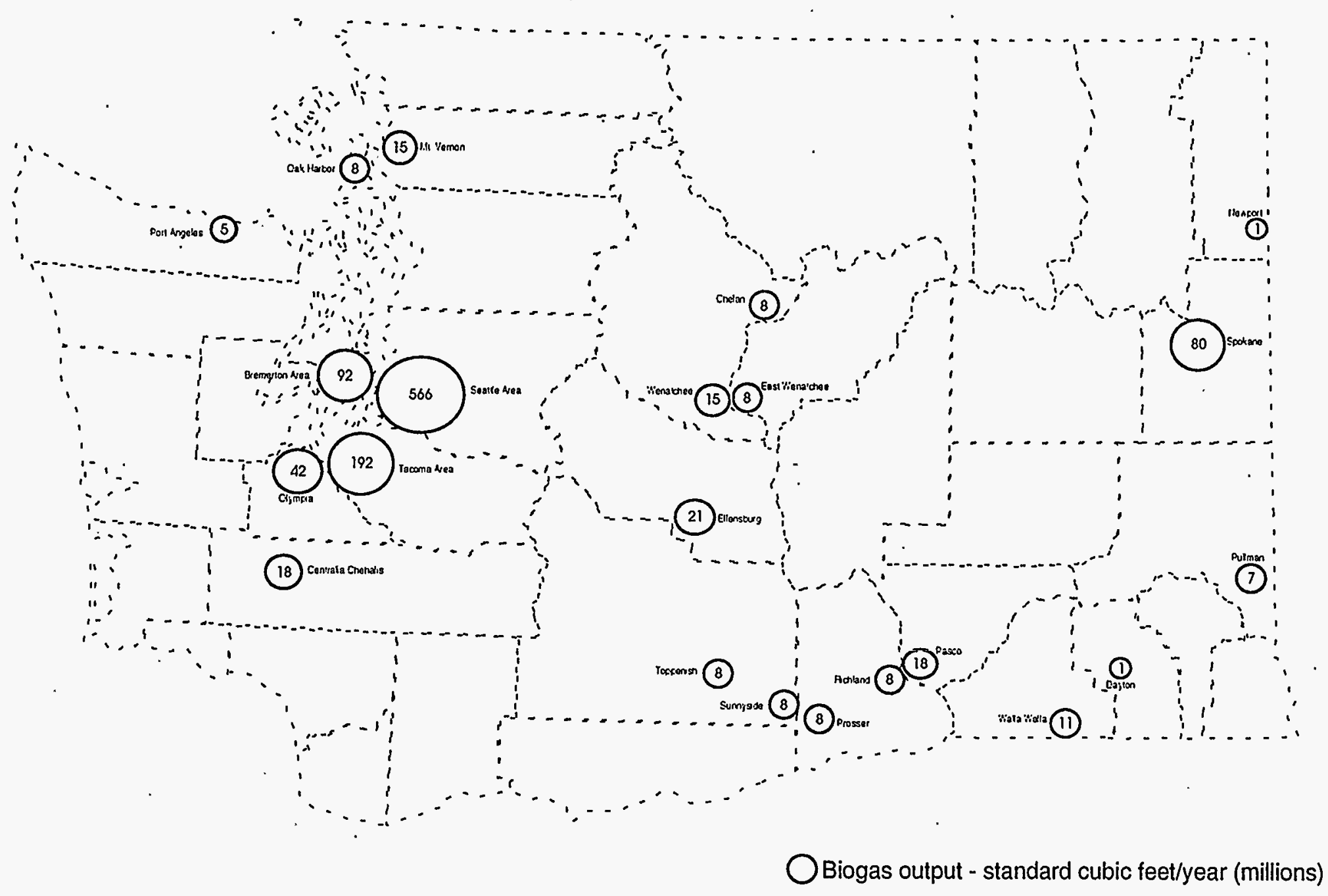

Figure 3

1993 Washington State Sewage Treatment Plant Biogas

Source: WSEO, 1994 Washington State Directory of Biomass Energy Facilities 
Table 4

1993 Washington State Sewage Treatment Plant Biogas Production

Sorted by Biogas Output

\begin{tabular}{|c|c|c|c|c|}
\hline Sewage Treatment Plant & County & $\begin{array}{c}\text { Average } \\
\text { Biogas } \\
\text { Output } \\
\text { (Million } \\
\text { SCF/Year) } \\
\end{array}$ & $\begin{array}{c}\text { Gross } \\
\text { Energy } \\
\text { Equivalent } \\
\text { (Million } \\
\text { Btu/Year) } \\
\end{array}$ & End Use \\
\hline Metro West Point & King & 300 & 180,000 & Space \& process heat, electricity \\
\hline Renton & King & 185 & 111,000 & Pipeline gas \\
\hline Tacoma STP-1 & Pierce & 120 & 72,000 & Space \& process heat \\
\hline Spokane & Spokane & 80 & 48,000 & Space \& process heat, air conditioning \\
\hline Port Orchard & Kitsap & 55 & 33,000 & Space \& process heat \\
\hline Chambers Creek & Pierce & 52 & 31,200 & Space \& process heat \\
\hline LOTT & Thurston & 42 & 25,200 & Process heat, back-up electricity \\
\hline Newport & Pend Oreille & 30 & 18,000 & Process heat \\
\hline Des Moines Creek & King ${ }^{\circ}$ & 22 & 13,200 & Space \& process heat \\
\hline Central Kitsap & Kitsap & 23 & 13,800 & Space \& process heat \\
\hline Ellensburg & Kittitas & 21 & 12,600 & Process heat \\
\hline Pasco & Franklin & 18 & 10,800 & Space \& process heat \\
\hline Metro Alki & King & 15 & 9,000 & Space \& process heat \\
\hline Salmon Creek & King & 15 & 9,000 & Space \& process heat, excess flared \\
\hline Miller Creek & King & 15. & 9,000 & Space \& process heat, excess flared \\
\hline Wenatchee & Chelan & 15 & 9,000 & Process heat \\
\hline Mount Vernon & Skagit & 15 & 9,000 & Space \& process heat \\
\hline Redondo & King & 14 & 8,400 & Space \& process heat \\
\hline Bremerton & Kitsap & $14^{2}$ & 8,400 & Process heat, back-up electricity \\
\hline Chehalis & Lewis & 13 & 7,800 & Process heat \\
\hline Puyallup & Pierce & 10 & 6,000 & Space \& process heat \\
\hline Walla Walla & Walla Walla & 9 & 5,400 & Process heat \\
\hline Chelan & Chelan & 8 & 4,800 & Flared \\
\hline Pullman & Whitman & 7 & 4,200 & Space and process heat \\
\hline Oak Harbor & Island & 8 & 4,800 & Process heat \\
\hline Prosser & Benton & 8 & 4,800 & Process heat \\
\hline Rainier State School & Pierce & 8 & 4,800 & Process heat \\
\hline Douglas County & Douglas & 8 & 4,800 & Process heat \\
\hline Richland & Benton & 8 & 4,800 & Space \& process heat \\
\hline Sunnyside & Yakima & 8 & 4,800 & Process heat \\
\hline Toppenish & Yakima & 8 & 4,800 & Process heat \\
\hline Centralia & Lewis & 5 & 3,000 & Space \& process heat, excess flared \\
\hline Port Angeles & Clallam & 5 & 3,000 & Process heat \\
\hline Tacoma STP-3 & Pierce & 2 & 1,200 & Space \& process heat \\
\hline College Place & Walla Walla & 2 & 1,200 & Space \& process heat \\
\hline Dayton & Columbia & 1 & 600 & Flared \\
\hline Total & & 1,169 & 701,400 & \\
\hline
\end{tabular}

-1Energy equivalent based on $600 \mathrm{Btu}$ per standard cubic foot of biogas

${ }^{2}$ Calculated by WSEO 


\section{Sewage Treatment Plants}

\section{Bremerton Wastewater Treatment Plant}

1600 Oyster Bay Ave.

Bremerton, WA 98310

Phone: (206) 479-4646

Contact: Tom Wamer

Plant design capacity:

Sewage (MGD): 15

Electrical generation (MW): $140 \mathrm{~kW}$

Average plant output:

Biogas (scf):

Electrical generation (MW): $70 \mathrm{kWh}$

End use(s): Process heat, heating digesters, standby power

\section{Central Kitsap Wastewater Treatment Plant}

12350 State Highway $303 \mathrm{NE}$

Poulsbo, WA 98370

Phone: (206) 876-7197

Contact: Ralph DeClements

Plant design capacity:

Sewage (MGD): 4.8

Electrical generation (MW): None

Average plant output:

Biogas (scf): 22.6673 million per year

Electrical generation (MW): None

End use(s): Space and process heat

\section{Centralia Wastewater Treatment Plant}

1401 W Mellen Street

Centralia, WA 98531

Phone: (206) 736-2853

Contact: Denise Lahmann, Administrator, or Ron Davis,

Manager

Plant design capacity:

Sewage (MGD): 4.3

Electrical generation (MW): Standby generator $250 \mathrm{~kW}$

three phase, $277 / 480$ volts
Average plant output:

Biogas (standard cubic feet): 5 million per year (anaerobic digestion)

Electrical generation (MW): None

End use(s): Space and process heat; excess flared in summer.

\author{
Chambers Creek Wastewater Treatment Plant \\ 10311 Chamber Creek Road W. \\ Tacoma, WA 98467-1040 \\ Phone: (206) 565-3013 \\ Contact: Larry McCaffrey
}

Plant design capacity:

Sewage (MGD): 18

Electrical generation (MW): None

Average plant output: $12.16 \mathrm{MGD}$

Biogas (scf): 51.5 million per year

Electrical generation (MW): None

End use(s): Space and process heat, heat digesters

\section{Chehalis Wastewater Treatment Plant \\ 1191 NW Shoreline Drive \\ Chehalis, WA 98532}

Phone: (206) 748-7187

Contact: Bill Pounds

Plant design capacity:

Sewage (MGD): 4.0 (average dry weather)

Electrical generation (MW): None

Average plant output:

Biogas (scf): Less than 15 million per year

Electrical generation (MW): None

End use(s): Process heat 


\section{Chelan Wastewater Treatment Plant}

S Robinson Street

Chelan, WA 98816

Phone: (509) 682-2211

Contact: Howard Merchant

Plant design capacity:

Sewage (MGD): 1.2 (new R.B.C. plant)

Electrical generation (MW): None

Average plant output: Unknown

Biogas (scf): Less than 10 million per year

Electrical generation (MW): None

End use(s): Flared

\section{College Place Wastewater Treatment Plant} 1880 Owens Rd.

Walla Walla, WA 99362-8115

Phone: (509) 525-0510, ext. 33

Contact: Al Rader

Plant design capacity:

Sewage (MGD): 1 dry, 2.55 wet

Electrical generation (MW): $48 \mathrm{k}$ Portable propane generator (back-up)

Average plant output:

Biogas (scf): 3.3

Electrical generation (MW): None

End use(s): Boiler, heat building

\section{Dayton Wastewater Treatment Plant}

Route 1, Box 19A

Dayton, WA 99328

Phone: (509) 382-2937

Contact: Charles D. Lowe

Plant design capacity:

Sewage (MGD): 0.60

Electrical generation (MW): None

Average plant output:

Biogas (scf): 886,220 per year

Electrical generation (MW): None

End use(s): flared
Des Moines Creek Wastewater Treatment Plant

P.O. Box 3487

Kent, WA 98032-0209

Phone: (206) 824-2760

Contact: Clint Read, Superintendent

Plant design capacity:

Sewage (MGD): 6.0

Electrical generation (MW): None

Average plant output:

Biogas (scf): 21.713 million

Electrical generation (MW): None

End use(s): Space and process heat

\section{Douglas County Sewer District}

P.O. Box 7129

East Wenatchee, WA 98801

Phone: (509) 884-2484

Contact: Roger C. Ray

Plant design capacity:

Sewage (MGD): 1.6

Electrical generation (MW): None Average plant output: $1 \mathrm{MGD}$

Biogas (scf): Less than 10 million per year

Electrical generation (MW): None

End use(s): Process heat

\section{Ellensburg Wastewater Treatment Plant}

Route 2, Box 13

Ellensburg, WA 98926

Phone: (509) 962-7277

Contact: Rick Bollinger

Plant design capacity:

Sewage (MG்D): 15

Electrical generation (MW): None

Average plant output:

Biogas (scf): 21 million per year

Electrical generation (MW): None

End use(s): Process heat and digester mixing 


\section{LOTT Wastewater Treatment Plant}

$500 \mathrm{~N}$ Adams Street

Olympia, WA 98507

Phone: (206) 753-8386

Contact: Tom Kolby

Plant design capacity:

Sewage (MGD): 22

Electrical generation (MW): Back-up

Average plant output:

Biogas (scf): 42.3 million per year

Electrical generation (MW): $1,726,807 \mathrm{kWh}$

End use(s): Power generation and process heat

\section{Metro Alki Wastewater Treatment Plant}

3380 Beach Drive SW

Seattle, WA 98116

Phone: (206) 684-2412

Contact: Dick Finger

Plant design capacity:

Sewage (MGD): 15

Electrical generation (MW): None

Average plant output:

Biogas (scf): 40,000 per day, 14.6 million per year

Electrical generation (MW): None

End use(s): Space and process heat

\section{Metro West Point Wastewater Treatment Plant} 1400 Utah St. W.

Seattle, WA 98199

Phone: (206) 684-1807

Contact: Gordon Gabrielson

Plant design capacity:

Sewage (MGD): 125

Electrical generation (MW): Gas production is no longer adequate to power three $1.3 \mathrm{MW}$ generator. Gas production should be adequate again in 1996.

Average plant output:

Biogas (scf): 300 million/year.

Electrical generation $(\mathrm{MW}): 1: 1$

End use(s): Space and process heat, electricity, equipment drives. Biogas also fuels influent pump engine $=500 \mathrm{~kW}$
Miller Creek Sewage Treatment Plant

Southwest Suburban Sewer District

1015 SW 174th Street

Seattle, WA 98166

Phone: (206) 244-2202

Contact: Clay Long

Plant design capacity:

Sewage (MGD): 6.4 (peak month)

Electrical generation (MW): None

Average plant output:

Biogas (scf): 50,000/day, 1.6 million per mo.

Electrical generation (MW): None

End use(s): Space and process heat, excess flared off

\section{Mount Vernon Sewer Department}

1401 Britt Road

Mount Vernon, WA 98273

Phone: (206) 336-6219

Contact: Chuck Saunders

Plant design capacity: Sewage (MGD): 4 average wet weather flow

Electrical generation (MW): None

Average plant output:

Biogas (scf): 15 million/year

Electrical generation (MW): None

End use(s): Space heat and process heat

\section{Newport Wastewater Treatment Plant}

S. 200 Washington Street

Newport, WA 99156

Phone: (509) 447-5611

Contact: Raymond D. King

Plant design capacity:

Sewage (MGD): 0.5

Electrical generation (MW): None

Average plant output:

Biogas (scf): 1.2 million per year

Electrical generation (MW): None

End use(s): Process heat 
Oak Harbor Wastewater Treatment Plant

3075 - 300 Avenue W

Oak Harbor, WA 98277

Phone: (206) 679-5551, ext. 230

Contact: Jim Croft

Plant design capacity:

Sewage (MGD): .7

Electrical generation (MW): None

Average plant output:

Biogas (scf): 1.4 million per year

Electrical generation (MW): None

End use(s): Process heating. Digested sludge is used as fertilizer.

\section{Pasco Wastewater Treatment Plant}

1015 S. Grey Street

P.O. Box 293

Pasco, WA 99301

Phone: (509) 545-3463

Contact: Harold Posthuma

Plant design capacity:

Sewage (MGD): 4.25

Electrical generation (MW): None

Average plant output:

Biogas (scf): 50,000 per day

Electrical generation (MW): None

End use(s): Space and process heat

\section{Port Angeles Wastewater Treatment Plant} 1509 E Columbia Street

Port Angeles, WA 98362

Phone: (206) 451-0411, ext. 165

Contact: Jim Abernathy

Plant design capacity:

Sewage (MGD): 3.2

Electrical generation (MW): None

Average plant output:

Biogas (scf): 6.2 million per year

Electrical generation (MW): None

End use(s): Process heat
Port Orchard/Kitsap County Sewer District No.5

1165 Beach Drive

Port Orchard, WA 98366

Phone: (206) 895-2440

Contact: Douglas W. Martin, Plant Manager

Plant design capacity:

Sewage (MGD): 2.8

Electrical generation (MW): None

Average plant output: $1.2 \mathrm{MGD}$

Biogas (scf): 50-60 million per year

Electrical generation (MW): None

End use(s): Space and process heat, digester mixing

\section{Prosser Wastewater Treatment Plant}

Box 271

Prosser, WA 99350

Phone: (509) 786-1101

Contact: Greg Pietz

Plant design capacity:

Sewage (MGD): 1.5 (wastewater)

Electrical generation (MW): None

Average plant output:

Biogas (scf): Less than 10 million per year

Electrical generation (MW): None

End use(s): Process heat

Pullman Wastewater Treatment Plant P.O. Box 249

Pullman, WA 99163

Phone: (509) 334-4555, ext. 233

Contact: Patrick J. Wiltzius

Plant design capacity:

Sewage (MGD): 4.3

Electrical generation (MW): None

Average plant output:

Biogas (scf): 6.9 million (per 1993 year)

Electrical generation (MW): None

End use(s): Space and process heat 


\section{Puyallup Pollution Control Facility}

2028 River Road

Puyallup, WA 98373

Phone: (206) 841-5511

Contact: B. Michael Webb

Plant design capacity:

Sewage (MGD): 10.7

Electrical generation (MW): None

Average plant output:

Biogas (scf): 10 million per year

Electrical generation (MW): None

End use(s): Space and process heat. Sludge is used as compost mixed with saw-dust and used by nurseries for flowering plants and trees.

\section{Rainier State School Sewage Treatment Plant}

P.O. Box 600

Buckley, WA 98321

Phone: (206) 829-1734, ext. 3042

Contact: Roy Camphell

Plant design capacity:

Sewage (MGD): .15

Electrical generation (MW): None

Average plant output:

Biogas (scf): .15

Electrical generation (MW): None

End use(s): Heating the digester, supple-mented w/natural gas

\section{Redondo Wastewater Treatment Plant}

515 S 288th Street

Redondo, WA 98054

Phone: (206) 839-7441

Contact: Lee Schumacher

Plant design capacity:

Sewage (MGD): 4.32 average annual, 13.80 peak

hydraulic, and 5.47 average wet weather

Electrical generation (MW): None

Average plant output:

Biogas (scf): 14.287 million per year

Electrical generation (MW): None

End use(s): Space and process heat. Excess flared.
Renton Wastewater Treatment Plant

1200 Monster Road SW

Renton, WA 98055

Phone: (206) 684-2412

Contact: Dick Finger, Process Control Supervisor

Plant design capacity:

Sewage (MGD): 72

Electrical generation (MW): None

Average plant output:

Biogas (scf): 506,000 per day

Electrical generation (MW) $\cdots$ None

End use(s): Pipeline gas

\section{Richland Wastewater Treatment Plant}

P.O. Box 190

Richland, WA 99352

Phone: (509) 943-7481

Contact: Roy Carlson

Plant design capacity:

Sewage (MGD): 8.9 average flow

Electrical generation (MW): $95 \mathrm{~kW}$, May-October

Average plant output:

Biogas (scf): 21,000 per day

Electrical generation (MW): None

End use(s): Space and process heat

Salmon Creek Wastewater Treatment Plant Southwest Suburban Sewer District

12550 Shorewood Drive SW

Seattle, WA 98146

Phone: (206) 243-7770

Contact: John Mutton

Plant design capacity:

Sewage (MGD): 5.8 (peak month)

Electrical generation (MW): None

Average plant output:

Biogas (scf): 42,000 per day

Electrical generation (MW): None

End use(s): Process and building heat, excess flared off 
Spokane Wastewater Treatment Plant

4401 N. A.L White Parkway

Spokane, WA 99205

Phone: (509) 625-4600

Contact: Bob Darilek

Plant design capacity:

Sewage (MGD): $44,000,000$

Electrical generation (MW): $300 \mathrm{~kW}$

Average plant output:

Biogas (scf): 80 million

Electrical generation (MW): $.3 \mathrm{MW}$

End use(s): Space and process heat, air conditioning, absorption chiller

\section{Sunnyside Wastewater Treatment Plant}

818 E. Edison Avenue

Sunnyside, WA 98944

Phone: (509) 837-5206

Contact: Charles Kennedy

Plant design capacity:

Sewage (MGD): 3

Electrical generation (MW): None

Average plant output:

Biogas (scf): Less than 10 million per year

Electrical generation (MW): None

End use(s): Process heat

Tacoma Wastewater Treatment Plant-1

2201 Portland Avenue

Tacoma, WA 98421

Phone: (206) 591-2014, ext. 4301

Contact: Charles Montgomery

Plant design capacity:

Sewage (MGD): 28

Electrical generation (MW): None

Average plant output:

Biogas (scf): 120 million per year

Electrical generation (MW): None

End use(s): Space and process heat,

hot water, autos
Tacoma Wastewater Treatment Plant-3

4002 Waterview Street

Tacoma, WA 98507

Phone: (206) 591-2014 ext. 4301

Contact: Charles Montgomery

Plant design capacity:

Sewage (MGD): Less than 10

Electrical generation (MW): None

Average plant output:

Biogas (scf): 2 million per year

Electrical generation (MW): None

End use(s): Space and process heat $-60 \%$ of TP-3 now processed at TP-1.

\section{Toppenish Wastewater Treatment Plant}

City Hall

21 West 1st Street

Toppenish, WA 98948

Phone: (509) 865-4089

Contact: Ed Martindale

Plant design capacity:

Sewage (MGD): 1.35

Electrical generation (MW): None

Average plant output:

Biogas (scf): Less than 10 million per year

Electrical generation (MW): None

End use(s): Process heat

\section{Walla Walla Wastewater Treatment Plant} 571 Hatch Street

Walla Walla, WA 99362

Phone: (509) 527-4509

Contact: Al Proudy

Plant design capacity:

Sewage (MGD): 10.8 dry flow, 15.00 wet flow

Electrical generation (MW): None

Average plant output:

Biogas (scf): 25,000 per day

Electrical generation (MW): None

End use(s): Process heat 


\section{Wenatchee Water Pollution Control}

$201 \mathrm{~N}$ Worthen Street

P.O. Box 519

Wenatchee, WA 98801

Phone: (509) 663-8416

Contact: Tom Hardie

Plant design capacity:

Sewage (MGD): 5

Electrical generation (MW): None

Average plant output:

Biogas (scf): 15 million + per year

Electrical generation (MW): None

End use(s): Space and process heat 


\section{Sewage Treatment Plant Listing Changes from 1992 Edition}

Deleted

McCleary Sewage Treatment Facility
Cause

Unable to contact facility
County

Mason
Added

College Place Wastewater Treatment Facility

\section{County}

Walla Walla 


\title{
Chapter 2
}

\section{Biomass Combustion}

\author{
Chemical Recovery \\ Municipal Solid Waste \\ Waste Wood Combustion
}


Chemical Recovery 


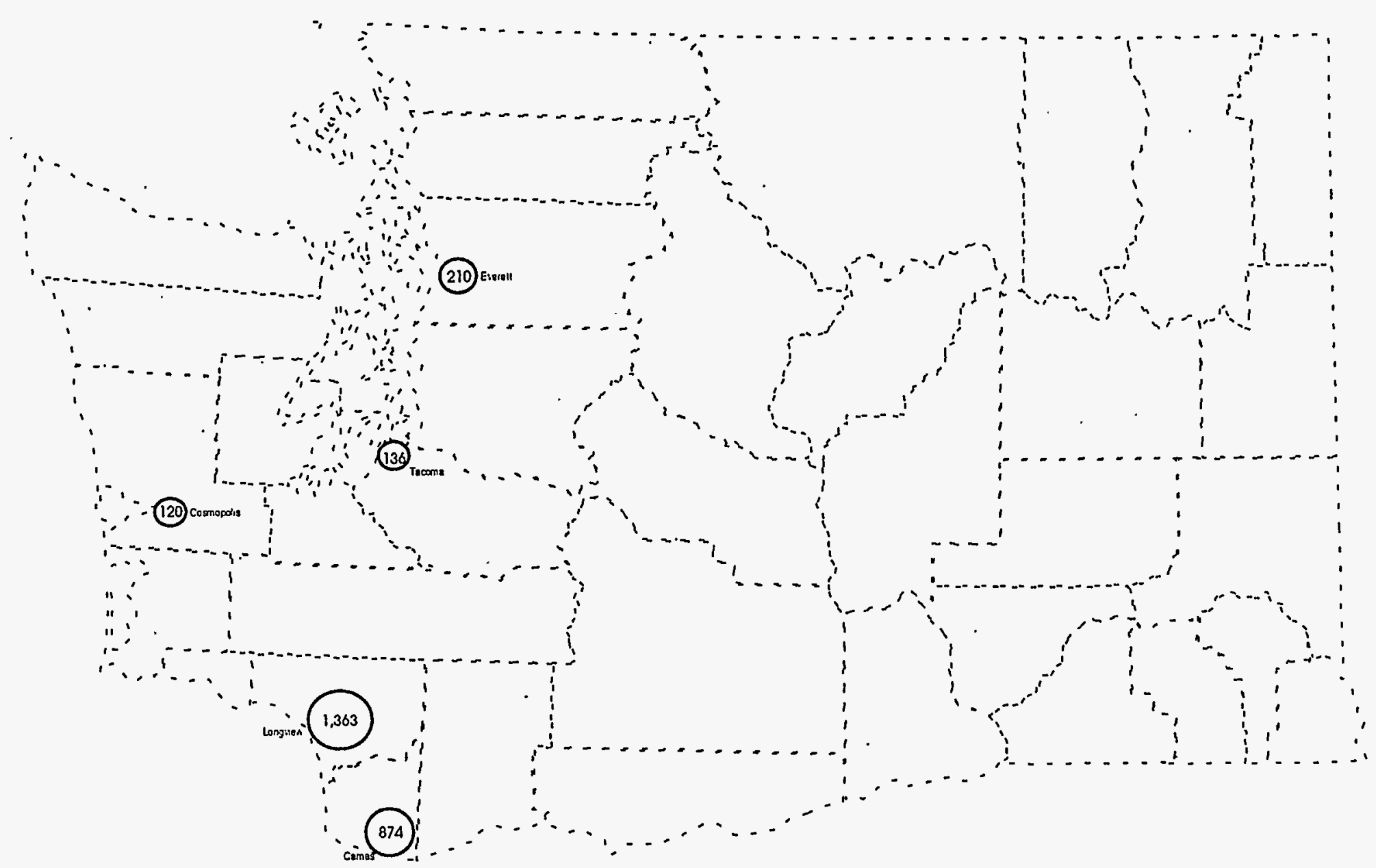

Figure 4

Ślids Burned - tons/year (thousands)

1993 Washington State

Solids Burned at Chemical Recovery Facilities

Source: WSEO, 1994 Washington State Directory of Biomass Energy Facilities 
Table 5

\section{Washington State Chemical Recovery Facilities}

Sorted by Solids Burned

\begin{tabular}{|c|c|c|c|c|}
\hline Facility Name & County & $\begin{array}{c}\text { Solids } \\
\text { Burned } \\
\text { (tons/year) }\end{array}$ & $\begin{array}{c}\text { Gross Energy } \\
\text { Equivalent }{ }^{1} \\
\text { (million Btu/year) }\end{array}$ & End Use \\
\hline James River & Clark & 874,200 & $11,364,600$ & Process steam \\
\hline Longview Fibre Company & Cowlitz & 759,900 & $9,878,700$ & $\begin{array}{l}\text { Process steam, heating, } \\
\text { cogenerated electricity ( } 48 \mathrm{MW} \text { ) }\end{array}$ \\
\hline Weyerhaeuser Paper Co. & Cowlitz & 603,000 & $7,839,000$ & $\begin{array}{l}\text { Process steam, cogenerated } \\
\text { electricity }(8.9 \mathrm{MW})\end{array}$ \\
\hline Scott Paper & Snohomish & 210,000 & $2,730,000$ & Process steam \\
\hline Simpson Tacoma Kraft & Pierce & 136,199 & $1,770,587$ & Process steam \\
\hline Weyerhaeuser Company & Grays Harbor & $120,400^{2}$ & $1,565,200$ & $\begin{array}{l}\text { Process steam, cogenerated } \\
\text { electricity }(11 \mathrm{MW})\end{array}$ \\
\hline Total & & $2,703,699$ & $35,148,087$ & \\
\hline
\end{tabular}

IEnergy equivalent calculated at 13 million Btu per ton of solids burned

${ }^{2}$ WSEO estimate, figure based on average steam output and psig 


\section{Chemical Recovery Facilities}

James River

NE 4th and Adams Street

Camas, WA 98607

Phone: (206) 834-8161

Contact:: W. W. Vautzelfden

Type of chemicals recovered: Spent sulfite liquor

Solids burned/yr (tons): 176,100

End use(s): Process steam

Supplemental fuel used: Natural gas

Plant design capacity: One

Steam: 263,000 lbs/hr @ 400 psig

Electric generation: N/A

Average output:

Steam: 224,000 lbs/hr @ 400 psig

Electric generation: N/A

Type of furnace: Chemical recovery

Manufacturer: B \& W

Type of pollution control: Wet scrubber

\section{Also, for James River}

Type of chemicals recovered: Spent kraft pulping liquor

Solids burned/yr (tons): 698,100

End use(s): Process steam

Supplemental fuel used: Natural gas and oil

Plant design capacity: Two boilers

Steam: \#3 - 343,000 lbs/hr @ 600 psig

\#4 - 453,000 lb/hr@ 400 psig

Electric generation: None

Average output: Steam: 730,000 lbs @ 400 psig

Electric generation: None

Type of furnace: Chemical recovery

Manufacturer: Both boilers - Combustion Engineering

Type of pollution control: ESP and wet scrubbers

\section{Longview Fibre Company}

P.O. Box 3000

Longview, WA 98632

Phone: (206) $425-1550$

Contact: R.W. Williams

Type of chemicals recovered: Spent sulfate liquor

Solids Burned/yr (tons): 759,900 (1993)

End use(s): Process steam, cogenerated electricity

(continued on next column)
Supplemental fuel used: None

Plant design capacity (number of boilers): Five boilers (\#14-400 tons, \#15-700 tons, \#18-710 tons, \#19-1650 tons, \#22-1850 tons)

Steam: \#14 164,500, \#15-316,000, \#18-367,000, \#19-579,800, \#22-622,000 all boilers @ 800 psig Electric generation: $60 \mathrm{MW}$

Average output: (1991) $8,780,896,000 \mathrm{lbs}$ of steam

Steam: 1,202,698 lbs/hr @ $806 \mathrm{psig}$

Electric generation: $48 \mathrm{MW}$ (1991)

Type of furnace: \#14\#19 Dual Drum, \#22 Single Drum

Manufacturer: All-Combustion Engineering

Type of pollution control: \#14-\#19 wet bottom electrostatic precipitators, \#22 dry bottom

electrostatic precipitator, $\# 15$ is equipped with a scrubber after its precipitator

\section{Scott Paper}

2600 Federal Avenue

Everett, WA 98220

Phone: (206) 259-7333

Contact: Alex M. Hood

Type of chemicals recovered: Spent sulfite liquor

Solids burned/yr (tons): 210,000

End use(s): Process steam.

Supplemental fuel used: Natural Gas

Plant design capacity: 1 boiler

Steam: Operating $381,000 \mathrm{lbs} / \mathrm{hr} \max 300 \mathrm{psig}$

$-520 \mathrm{~F}$; design $340,000 \mathrm{lbs} / \mathrm{hr}$ max $825 \mathrm{psig}$ -

$750 \mathrm{~F}$

Electric generation (MW): 0

Average output:

$$
\text { Steam: } 320,000 \mathrm{lbs} / \mathrm{hr}
$$

@ 300 psig at 520 F

Electric generation: None

Type of furnace: 2 Pass

Manufacturer. B \& W

Type of pollution control: All in series:

1) Cooling tower with wet scrubber,

2) NH3 absorption tower,

3) Dyna-Wave caustic scrubber, and

4) Demisters. 


\section{Simpson Tacoma Kraft Company}

801 Portland Avenue

Tacoma, WA 98421

Phone: (206) 572-2150

Contact: David McEntee

Type of chemicals recovered: Spent sulfite liquor

Solids burned/yr (tons): 746,298 lbs/day

End use(s): Process steam

Supplemental fuel used: Bunker C fuel oil

Plant design capacity: 2 boilers

Steam: 590,000 lbs/hr @ 425 psig

Electric generation (MW): None

Average output:

Steam: 550,000 lbs/hr @ 425 psig

Electric generation (MW): None

Type of furnace: 2 drum natural circulation

Manufacturer: Combustion engineering

Type of pollution control: ESP/ESP \& wet scrubbers

\section{Weyerhaeuser Company}

P.O. Box 1000

Cosmopolis, WA 98537.

Phone: (206) 532-7110

Contact: Paul W. Kelso

Type of chemicals recovered: Spent sulfite liquor Solids burned/yr (tons):

End use(s): Electricity and process steam

Supplemental fuel used: No. 6 fuel oil

Plant design capacity (number of boilers): 3

Steam: 348,000 lbs/hr @ 825 psig

Electric generation: $15 \mathrm{MW}$

Average output:

Steam: 25,000 1bs/hr @ 825 psig

Electric generation: $11 \mathrm{MW}$

Type of furnace: 2 with firebrick furnace,

1 with water cooled furnace

Manufacturer: Babcock \& Wilcox Co.

Type of pollution control: Packed towers

\section{Weyerhaeuser Paper Company}

P.O. Box 188

Longview, WA 98632

Phone: (206) 425-2150 Ext. 5486

Contact: Jeff Inman

Type of chemicals recovered: Sulfate and neutral Sulfite spent cooking liquors

Solids burned/yr (tons): 603,000 tons

End uses(s): Process steam, heating, electricity generation

Supplemental fuel used: No. 6 Fuel Oil

Plant design capacity: One boiler

Steam: $619,000 \mathrm{lb} / \mathrm{hr} @ 700 \mathrm{psig}$

and $730 \mathrm{~F}$

Electric Generation: $8.9 \mathrm{MW}$

Average outpuit:

Steam: 507,000 1b/hr@ 600 psig and $720 \mathrm{~F}$

Electric Generation: $8.9 \mathrm{MW}$

Type of Furnace: Tomlinson, two drum, membrane wall, low-odor

Manufacturer: Babcock and Wilcox Co.

Type of Pollution Control: Dry bottom electro static precipitator

* Making changes in chemical recovery - expect increases in 1995. 


\section{Chemical Recovery Facilities Listing Changes from 1992 Edition}

No facilities addes or deleted. 


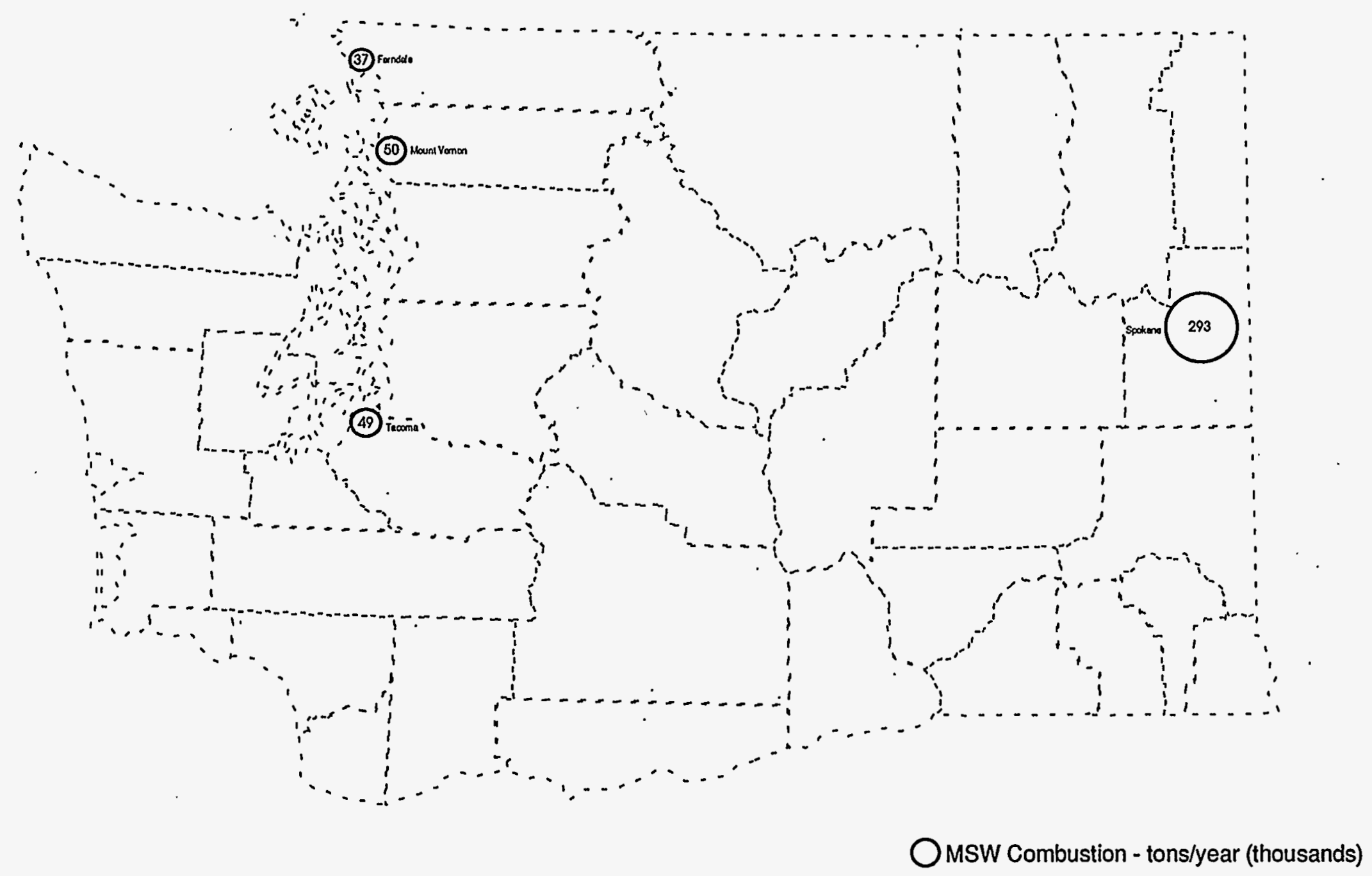

Figure 5

\section{Washington State Municipal Solid Waste Combustion}

Source: WSEO, 1994 Washington State Directory of Biomass Energy Facilities 
Table 6

\section{Municipal Solid Waste Combustion}

Sorted by Annual Municipal Solid Waste (MSW) Consumption

\begin{tabular}{|l|l|r|r|l|}
\hline \multicolumn{3}{|c|}{ County $\begin{array}{c}\text { Annual MSW } \\
\text { Consumption } \\
\text { (Tons/Year) }\end{array}$} & $\begin{array}{c}\text { Gross Energy } \\
\text { Equivalent }{ }^{1} \\
\text { (Million Btu/Year) }\end{array}$ & End Uses \\
\hline Spokane Trash-to-Energy & Spokane & 293,000 & $2,930,000$ & Supply electricity to PSP\&L \\
\hline Skagit Co. Resource Recovery & Skagit & 50,000 & 500,000 & Supply electricity to PSP\&L \\
\hline Tacoma Steam Plant \#2 & Pierce & 49,000 & $637,000^{2}$ & Supply electricity to PSP\&L \\
\hline Recomp of Washington, Inc. & Whatcom & 36,500 & 365,000 & $\begin{array}{l}\text { Electricity, steam for } \\
\text { mushroom plant }\end{array}$ \\
\hline Total & & 428,500 & $4,432,000$ & \\
\hline
\end{tabular}

${ }^{1}$ Energy equivalent based on 10 million Btu per ton of municipal solid waste

${ }^{2}$ Energy equivalent based on 13 million Btu per ton of refuse derived fuel 


\section{Municipal Solid Waste Combustion Facilities .}

Recomp of Washington, Inc.

1524 Slater Road

Ferndale, WA 98248

Phone: (206) 676-0660

Contact: Frank Moscone, President

Type of biomass fuel: Municipal solid waste

Source of fuel: City of Bellingham and Whatcom Co.

Annual MSW fuel consumed: 36,500

End use(s): Electricity, steam for mushroom plant

Plant design capacity: 100 tons per day

Heat (million Btu/hr):

Steam: 25,000 lbs $/ \mathrm{hr} @ 400$ psig

Electrical Generation (MW): 2.0

Average plant output:

Heat (million Btu/hr):

Steam: 25,000 lbs/hr @ 400 psig

Electrical Generation (MW): 2.0

Type of combustor/furnace: Modular Starved Air

Manufacturer: Consumat

Type of boiler: Water tube, verticle

Boiler manufacturer:

Type of pollution control: Scrubber baghouse

\section{Skagit County Resource Recovery Facility}

1200 W Ovenell Road

Mount Vernon, WA 98273

Phone: (206) 336-9400

Contact: Donald King

Type of MSW fuel: Municipal solid waste

Source of fuel: Skagit County

Annual biomass fuel consumed: 50,000 tons

End use(s): Provide electricity to Puget Power

Plant design capacity: 178 tons per day

Heat (million Btu/hr): 1600

Steam: 40,000 lbs/hr@ 450 psig

Electrical Generation (MW): 2.5

Average plant output: 14 tons per day

Heat (million Btu/hr):

Steam: 40,000 lbs/hr@ @ 450 psig

Electrical Generation (MW): 2.5

Type of combustor/furnace: Rotary Kiln

Manufacturer: Tecnitalia

Type of boiler: Water Tube

Boiler manufacturer: Zurn

Type of pollution control: Acid gas scrubber \& baghouse
Spokane Trash-to-Energy Facility

W. 808 Spokane Falls Blvd

Spokane, WA 99201

Phone: (509) 456-7403

Contact: Damon Taam

Type of biomass fuel: Municipal Solid Waste

Source of fuel: Spokane County

Annual biomass consumed: 293,000 tons/yr

End use(s): Supply electric power to PSP\&L, Inc.

Plant design capacity: 800 tons/day

Heat (million Btu/hr): 250 million Btu

Steam: $230,000 \mathrm{lb} / \mathrm{hr} @ 900 \mathrm{psig} / 830^{\circ} \mathrm{F}$

Electrical Generation (MW): $26 \mathrm{MW}$

Average plant output:

Heat (million Btu/hr):

Steam: 230,000 lbs@ 900 psig/830 $\mathrm{F}$

Electrical Generation: $26 \mathrm{MW}-4 \mathrm{MW}$ used in

plant, $22 \mathrm{MW}$ sold to PSP\&L

Type of combustion/furnace: Von Roll reciprocating

Manufacturer: Wheelabrator

Type of boiler: Waterwall Boiler

Manufacturer: Babcock \& Wilcox

Type of pollution control: Dry scrubbers, fabric filters, \& . de NOx

\section{Tacoma Steam Plant No. 2}

Tacoma City Light

P. O. Box 11007

Tacoma, WA 98411

Phone: (206) 383-9601

Contact: Mark Gamble

Type of biomass fuel: RDF, hog fuel \& coal

Source of fuel: City of Tacoma

Annual MSW fuel consumed: 49,000 tons (1993)

End use(s): Electricity

Plant design capacity: 300 tons RDF/day Heat: (million Btu/hr): $831 \mathrm{RDF} /$ wood/coal

Steam: 528,000 lbs/hr @ 382 psig

Electrical Generation (MW): $43 \mathrm{MW}$ net

Average plant output: 108 tons RDF/day (5 day week)

Heat (million Btu/hr):

Steam: 400,000 lbs/hr @ 382 psig

Electrical Generation (MW): $29 \mathrm{MW}$

Type of combustor/furnace: Fluidized bed

Manufacturer: Energy Products of Idaho

Type of boiler: 3 Drum Sterling

Boiler manufacturer: Puget Sound Boiler

Type of pollution control: Limestone in bed, baghouses 


\section{Municipal Solid Waste Facilities \\ Listing Changes from 1992 Edition}

No additions or deletions. 


\section{Waste Wood Combustion}




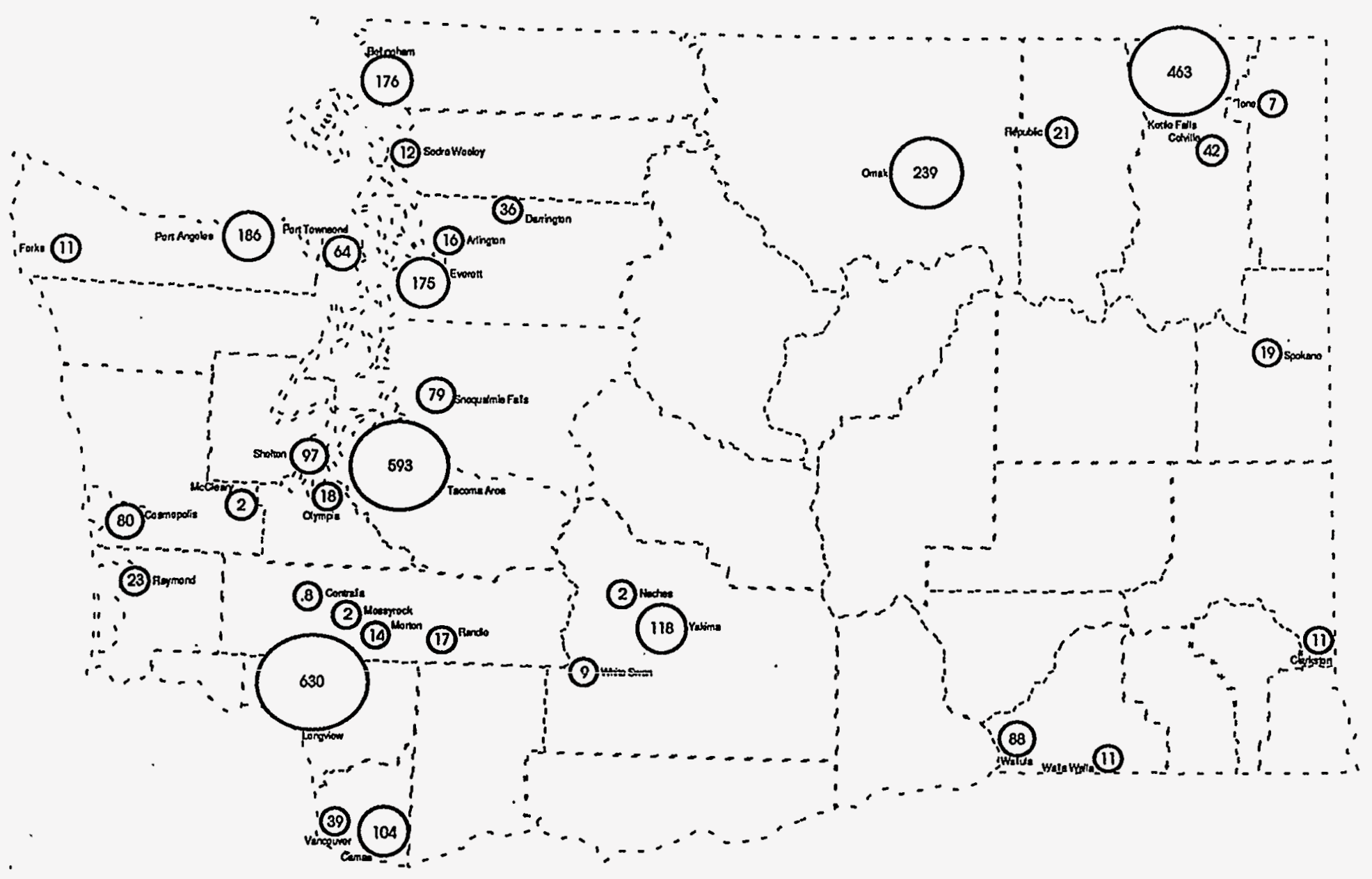

Waste wood consumed - bone dry tons/year (thousands)

Figure 6

1993 Washington State Waste Wood Combustion

Source: WSEO, 1994 Washington State Directory of Biomass Energy Facilities 
Table 7

1993 Waste Wood Combustion

Sorted by Annual Waste Wood Consumption

\begin{tabular}{|c|c|c|c|c|}
\hline Facility Name & County & $\begin{array}{c}\text { Annual } \\
\text { Waste Wood } \\
\text { Consumption } \\
\text { (BDTs/Yr) }\end{array}$ & $\begin{array}{c}\text { Gross Energy } \\
\text { Equivalent } \\
\text { (Million Btu/Yr) }\end{array}$ & End Uses \\
\hline $\begin{array}{l}\text { Weyerhaeuser } \\
\text { Washington Water Power } \\
\text { Tacoma Steam Plant No. } 2 \\
\text { Omak Wood Products } \\
\text { Simpson Tacoma Kraft } \\
\text { Scott Paper } \\
\text { Georgia-Pacific } \\
\text { Boise Cascade } \\
\text { Longview Fibre } \\
\text { Boise Cascade } \\
\text { Boise Cascade } \\
\text { James River } \\
\text { Rayonier } \\
\text { Simpson Timber } \\
\text { Boise Cascade } \\
\text { Weyerhaeuser } \\
\text { Weyerhaeuser } \\
\text { Port Townsend Paper } \\
\text { Daishowa America } \\
\text { Fort Vancouver Plywood } \\
\text { Summit Timber Power House } \\
\text { Colville Indian Precision Pine } \\
\text { K-Ply } \\
\text { Plum Creek Manufacturing } \\
\text { Weyerhaeuser } \\
\text { Simpson Door } \\
\text { Vaagen Brothers Lumber } \\
\text { W.I. Forest Products } \\
\text { GN Plywood } \\
\text { Hardel Mutual Plywood } \\
\text { Vaagen Brothers Lumber } \\
\text { Cowlitz Stud } \\
\text { Buffelen Woodworking } \\
\text { Morton Forest } \\
\text { Goodyear-Nelson } \\
\text { Northwest Hardwoods } \\
\text { Guy Bennett Lumber } \\
\text { Allen Logging } \\
\text { Jeld-Wen Fiber of WA } \\
\text { Shelton Corrections Center } \\
\text { Jeld-Wen of Everett } \\
\text { Vaagen Brothers Lumber } \\
\text { a }\end{array}$ & \begin{tabular}{|l|} 
Cowlitz \\
Stevens \\
Pierce \\
Okanogan \\
Pierce \\
Snohomish \\
Whatcom \\
Pierce \\
Cowlitz \\
Yakima \\
Stevens \\
Clark \\
Clallam \\
Mason \\
Walla Walla \\
Grays Harbor \\
King \\
Jefferson \\
Clallam \\
Clark \\
Snohomish \\
Okanogan \\
Clallam \\
Stevens \\
Pacific \\
Grays Harbor \\
Ferry \\
Spokane \\
Whatcom \\
Thurston \\
Stevens \\
Lewis \\
Pierce \\
Lewis \\
Skagit \\
Snohomish \\
Asotin \\
Clallam \\
Yakima \\
Mason \\
Snohomish \\
Pend Oreille \\
\end{tabular} & $\begin{array}{c}500,000 \\
350,000 \\
247,940 \\
210,240 \\
174,000 \\
168,000 \\
157,000 \\
153,973 \\
130,296 \\
118,000 \\
113,399 \\
104,000 \\
98,573 \\
89,000 \\
88,176 \\
80,000 \\
78,939 \cdot 2 \\
64,217 \\
63,600 \\
38,500 \\
36,500 \\
28,560 \\
24,000 \\
23,937 \\
23,091 \\
21,600 \\
21,000 \\
19,332 \\
19,200 \\
17,977 \\
17,885 \\
16,647 \\
15,573 \\
13,722 \\
12,351 \\
11,277 \\
11,242 \\
10,752 \\
8,750 \\
7,975 \\
7,000 \\
6,643 \\
\end{array}$ & $\begin{array}{r}8,500,000 \\
5,950,000 \\
4,214,980 \\
3,574,080 \\
2,958,000 \\
2,856,000 \\
2,669,000 \\
2,617,541 \\
2,215,032 \\
2,006,000 \\
1,927,783 \\
1,768,000 \\
1,675,741 \\
1,513,000 \\
1,498,992 \\
1,360,000 \\
1,341,963 \\
1,091,689 \\
1,081,200 \\
654,500 \\
620,500 \\
485,520 \\
408,000 \\
406,929 \\
\cdot 392,547 \\
367,200 \\
357,000 \\
328,644 \\
326,400 \\
305,609 \\
304,045 \\
282,999 \\
264,741 \\
233,274 \\
209,967 \\
191,709 \\
191,114 \\
182,784 \\
148,750 \\
135,575 \\
119,000 \\
112,931 \\
\end{array}$ & $\begin{array}{l}\text { Process steam \& heat } \\
\text { Electric generation } \\
\text { Electric generation } \\
\text { Electric gen., proc. steam \& heat } \\
\text { Process steam \& heat } \\
\text { Process steam \& heat } \\
\text { Process steam \& heat } \\
\text { Process steam \& heat } \\
\text { Process steam \& heat } \\
\text { Process heat } \\
\text { Process steam \& heat } \\
\text { Electric gen., proc. steam \& heat } \\
\text { Process steam \& heat } \\
\text { Process steam \& heat } \\
\text { Process steam \& heat } \\
\text { Electric gen., proc. steam \& heat } \\
\text { Process steam \& heat } \\
\text { Electric gen., proc. steam \& heat } \\
\text { Process steam \& heat } \\
\text { Process steam \& heat } \\
\text { Process steam } \\
\text { Process steam \& heat } \\
\text { Process steam \& heat } \\
\text { Process steam \& heat } \\
\text { Process steam \& heat } \\
\text { Process steam \& heat } \\
\text { Process steam \& heat } \\
\text { Process steam \& heat } \\
\text { Process steam \& heat } \\
\text { Process steam \& heat } \\
\text { Process steam \& heat } \\
\text { Process steam \& heat } \\
\text { Process steam \& heat } \\
\text { Process steam \& heat } \\
\text { Process steam \& heat } \\
\text { Process steam \& heat } \\
\text { Process steam \& heat } \\
\text { Process \& heat } \\
\text { Pteam \& heat } \\
\text { Prom \& heat } \\
\text { Prom steat }\end{array}$ \\
\hline
\end{tabular}




\begin{tabular}{|c|c|c|c|c|}
\hline Facility Name & County & $\begin{array}{c}\text { Annual } \\
\text { Wood } \\
\text { Consumption } \\
\text { (BDTs/Yr) }\end{array}$ & $\begin{array}{c}\text { Gross Energy } \\
\text { Equivalent }{ }^{1} \\
\text { (Million Btu/Yr) }\end{array}$ & End Uses \\
\hline $\begin{array}{l}\text { Louisiana Pacific } \\
\text { West Coast Forest Products } \\
\text { Strauser Manufacturing } \\
\text { Layman's Lumber } \\
\text { DeGoede Bulb Farms } \\
\text { Washington State Penitentiary } \\
\text { Western State Hospital } \\
\text { Kinnear of Washington } \\
\text { Oeser Company, The } \\
\text { Fred Tebb \& Sons } \\
\text { WA Soldiers Home \& Colony } \\
\text { Coastcraft } \\
\text { Smith Street Mill } \\
\end{array}$ & \begin{tabular}{|l|} 
Walla Walla \\
Snohomish \\
Walla Walla \\
Yakima \\
Lewis \\
Walla Walla \\
Pierce. \\
Lewis \\
Whatcom \\
Pierce \\
Pierce \\
Pierce \\
Snohomish \\
\end{tabular} & $\begin{array}{l}6,563 \\
4,720 \\
3,000 \\
2,100 \\
1,625^{2} \\
1,600 \\
875 \\
770 \\
280 \\
153 \\
100 \\
\text { NA } \\
\text { NA } \\
\end{array}$ & $\begin{array}{r}111,571 \\
80,240 \\
51,000 \\
35,700 \\
27,625 \\
27,200 \\
14,875 \\
13,090 \\
4,760 \\
2,601 \\
1,700 \\
\text { NA } \\
\text { NA } \\
\end{array}$ & $\begin{array}{l}\text { Process steam \& heat } \\
\text { Process heat } \\
\text { Process steam \& heat } \\
\text { Process steam \& heat } \\
\text { Greenhouse heating } \\
\text { Process steam \& heat } \\
\text { Back-up fuel } \\
\text { Process steam \& heat } \\
\text { Process steam \& heat } \\
\text { Process steam \& heat } \\
\text { Back-up fuel } \\
\text { Process steam \& heat } \\
\text { Process heat }\end{array}$ \\
\hline Total & & $3,424,653$ & $58,218,931$ & \\
\hline
\end{tabular}

NA - Information not available

${ }^{1}$ Energy equivalent calculated at 17 million Btu per ton of biomass wood consumed

- ${ }^{2}$ Estimated by the Washington State Energy Office 


\section{Forest Products Industry Facilities}

\author{
Allen Logging Company \\ HC 80, Box 736 \\ Forks, WA 98331 \\ Phone: (206) 374-6000 \\ Contact: Gerry Lane
}

Type of business: Lumber and veneer

Type of biomass fuel: Mill residue

Source of fuel: In-house

Annual biomass fuel consumed: 15,360 green tons

Back-up fuel: None

End use(s): Kiln dryers

Plant design capacity:

Heat (Million Btu/hr):

Steam: 10,000 lbs/hr@ @ 110 psig

Electrical generation (MW): None

Average plant output:

Heat (Million Btu/hr):

Steam: 7,500 lbs/hr@ 110 psig

Electrical generation (MW): None

Type of combustor/furnace: Fuel cell

Manufacturer: Wellons

Type of boiler: Erie water tube - modified VL

Boiler manufacturer: Erie

Type of pollution control: Multicone

Reason for using wood fuel: Cost, availability

\section{Boise Cascade Corp. - Kettle Falls Lumber - Steam Boiler}

S. 110 Boise Road

Kettle Falls, WA 99141

Phone: (509) 738-6421

Contact: Rod Smith

Type of business: Lumber

Type of biomass fuel: Hog fuel, planner shavings \& sawdust

Source of fuel: In-house

Annual biomass fuel consumed: 57,451 green tons

Back-up fuel: None

End use(s): Dry kilns and unit heaters

Plant design capacity:

Heat (Million Btu/hr):

Steam: 50,000 lbs/hr @ 125 psig

Electrical generation (MW):

(continued on next column)
Average plant output:

Heat (Million Btu/hr):

Steam: 35,700 lbs/hr@ 125 psig

Electrical generation (MW):

Type of combuster/furnace: 3 Cell Cyclo-Blast

Manufacturer: Wellons

Type of boiler: Water tube

Boiler manufacturer: Nebraska Boiler Company

Type of pollution control: Dry type mechanical

Multicone collector

Reason for using wood fuel: Economics

\section{Boise Cascade Corp. - Kettle Falls \\ Plywood -- Fluid Bed Burners}

S. 110 Boise Road

Kettle Falls, WA 99141

Phone: (509) 738-6421

Contact: Rod Smith

Type of business: Plywood

Type of biomass fuel: Hog fuel, sawdust

Source of fuel: In-house

Annual biomass fuel consumed: 120,000 green tons

Back-up fuel: None

End use(s): Plywood veneer dryers (direct heat source)

Plant design capacity:

Heat (Million Btu/hr): 160

Steam:

Electrical generation (MW):

Average plant output:

Heat (Million Btu/hr): 120

Steam:

Electrical generation (MW):

Type of combuster/furnace: Fluid bed

Manufacturer: Energy Products of Idaho (E.P.I.)

Type of boiler: None

Boiler manufacturer:

Type of pollution control: 6" Multicone collector \& wet scrubber

Reason for using wood fuel: Economics 
Boise Cascade Corp. - Kettle Falls Lumber \& Sm. Log Mill - Steam Boiler

S. 110 Boise Road

Kettle Falls, WA 99141

Phone: (509) 738-6421

Contact: Rod Smith

Type of business: Lumber \& plywood

Type of biomass fuel: Hog fuel, sawdust \& plywood trim Source of fuel: In-house

Annual biomass fuel consumed: 24,674 dry tons

Back-up fuel: None

End use(s): Steam vats, plywood hot press, unit heaters

Plant design capacity:

Heat (Million Btu/hr):

Steam: 60,000 lbs/hr @ i25 psig

Electrical generation (MW):

Average plant output:

Heat (Million Btu/hr):

Steam: 28,640 lbs/hr@ 125 psig

Electrical generation (MW):

Type of combuster/furnace: field erected, stationary water cooled grate

Manufacturer: Riley Stoker Corporation

Type of boiler: Water tube, type

Boiler manufacturer: Riley Stoker Corporation

Type of pollution control: Dry type 9 " mechanical multicone collector + EGB (electrical gravel bed)

Reason for using wood fuel: Economics

\section{Boise Cascade Corporation}

4302 Chamber Creek Road

Steilacoom, WA 98388

Phone: (206) 588-2115

Contact: Darrell Lantz

Type of business: Pulp and paper

Type of biomass fuel: Hog fuel

Source of fuel: Various lumber companies (all Purchased)

Annual biomass fuel consumed: 153,973 BDTs hogged fuel plus 17,472 tons sludge primary clarifier

Back-up fuel: Industrial \#6 oil

- End use(s): Process steam, dryers

(continued on next column)
Plant design capacity: No. 5 hogged fuel boiler

Heat (Million Btu/hr): None

Steam: 150,000 lbs/hr@ 140 psig

Electrical generation (MW): None

Average plant output:

Heat (Million Btu/hr):

Steam: $120,000 \mathrm{lbs} / \mathrm{hr} @ 140 \mathrm{psig}$

Electrical generation (MW): None

Type of combuster/furnace:

Manufacturer: Kipper \& Sons

Type of boiler: Traveling grate, water wall

Boiler manufacturer: Kipper \& Sons

Type of pollution control: Multicóné collectors/fly asfi" reinjection, AER POL high energy wet scrubber

Reason for using wood fuel: Cost/availability vs. fossil fuel. Also, firm is equipped with a Cascade (Bacho design) fuel dryer utilizing flue gas.

\section{Boise Cascade Corporation}

P.O. Box 500

Wallula, WA 99363

Phone: (509) 547-2411

Contact: Greg Buxton, Energy Engineer

Type of business: Pulp and paperboard

Type of biomass fuel: Hog fuel

Source of fuel: Purchased

Annual biomass fuel consumed: 73,480 BDUs

Back-up fuel: Natural gas

End use(s): Process steam, dryers

Plant design capacity: $1 \mathrm{Hog}$ fuel boiler Heat (Million Btu/hr): 193

Steam: 201,000 lbs/hr @ 250 psig

Electrical generation (MW): None

Average plant output:

Heat (Million Btu/hr): 172

Steam: 179,000 lbs/hr@ @ 250 psig

Electrical generation (MW): None

Type of combuster/furnace: Sterling type, pin hole gaate

Manufacturer: Kipper

Type of boiler: Sterling type pinhold grate

Boiler manufacturer: Kipper

Type of pollution control: Mechanical, multicone scrubber,

Riley ventri-rod wet scrubber

Reason for using wood fuel: Economics 


\section{Boise Cascade Corporation}

P.O. Box 51

Yakima, WA 98901

Phone: (509) 453-3131

Contact: Dick Godfrey

Type of business: Lumber

Type of biomass fuel: Hog fuel

Source of fuel: In-house

Annual biomass fuel consumed: 118,000 dry tons

Back-up fuel: None

End use(s): Dry kilns, dryers

Plant design capacity:

Heat (Million Btu/hr):

Steam: 200,000 lbs/hr @ 250 psig

Electrical generation (MW): None

Average plant output:

Heat (Million Btu/hr):

Steam: 150,000 lbs/hr @ 250 psig

Electrical generation (MW):

Type of combuster/furnace: 3 Dutch ovens,

1 spreader stoker

Manufacturer:

Type of boiler: Water tube

Boiler manufacturer:

Type of pollution control: Multicone and wet scrubber

Reason for using wood fuel: Economics

\section{Buffelen Woodworking}

P.O. Box 1383

Tacoma, WA 98481

Phone: (206) 627-1191

Contact: Bill Jones

Type of business: Door

Type of biomass fuel: Mill residue

Source of fuel: In-house

Annual biomass fuel consumed:

Back-up fuel: Propane

End use(s): Dry kiln

Plant design capacity:

Heat (Million Btu/hr):

Steam: 55,000 lbs/hr @

Electrical generation (MW): None

(continued on next column)
Average plant output:

Heat (Million Btu/hr):

Steam: 25,000 lbs/hr @__ psig

Electrical generation (MW):

Type of combuster/furnace:

Manufacturer:

Type of boiler: Water tube

Boiler manufacturer: Riley Stoker

Type of pollution control: Wet scrubber

Reason for using wood fuel: Cost, availability

\section{Coastcraft, Inc. (Kroon, Inc.)*}

1002 E Street

Tacoma, WA 98421

Phone: (206) 272-1154

Contact: Paul Kroon, Owner

Type of business: Woodwork, windows, doors Type of biomass fuel: Mill residues, sawdust

Source of fuel: In-house

Annual biomass fuel consumed:

Back-up fuel: None

End use(s): Dry kiln \& heating

Plant design capacity:

Heat (Million Btu/hr):

Steam: $500 \mathrm{lbs/hr@}$ psig

Electrical generation (MW):

Average plant output:

Heat (Million Btu/hr):

Steam:___lbs/hr@___psig

Electrical generation (MW):

Type of combuster/furnace:

Manufacturer:

Type of boiler: Fire tube

Boiler manufacturer:

Type of pollution control: None

Reason for using wood fuel: By-product

*1991 Data 
Colville Indian Precision Pine Co.

P.O. Box 3293

Omak, Washington 98841

Phone: (509) 826-1921

Contact: Ron Holen

Type of business: Lumber

Type of biomass fuel: Hog fuel

Source of fuel: In-house

Annual biomass fuel consumed: 28,560 BDTs

Back-up fuel: None

End use(s): Dry kilns

Plant design capacity:

Heat (Million Btu/hr):

Steam: 40,000 lbs/hr @ 100 psig

Electrical generation (MW):

Average plant output:

Heat (Million Btu/hr):

Steam: 30,000 lbs/hr@100 psig

Electrical generation (MW):

Type of combuster/furnace:

Manufacturer: Wellons

Type of boiler: $220,000 \mathrm{lb} / \mathrm{hr}$. hog fuel fired single cells

Boiler manufacturer: Wellons hog fuel fired

Type of pollution control: Dry scrubber

Reason for using wood fuel: Economics

\section{Cowlitz Stud Company ${ }^{*}$}

\section{P.O. Box 219}

Randle, WA 98377

Phone: (206) 497-5030

Contact: Lloyd Cook or Charlie Allen

Type of business: Lumber

Type of biomass fuel: Hog fuel

Source of fuel: In-house

Annual biomass fuel consumed:

Back-up fuel: None

End use(s): Dry kilns

Plant design capacity:

Heat (Million Btu/hr):

Steam : $25,000 \mathrm{lbs} / \mathrm{hr}$ (Randle)

40,000 lbs/hr (Morton) @ 300 psig

Electrical generation (MW): None

(continued on next column)
Average plant output:

Heat (Million Btu/hr):

Steam: $16,250 \mathrm{lbs} / \mathrm{hr}$ (Randle); 26;000 lbs/hr (Morton)

both @ 300 psig

Electrical generation (MW): None

Type of combuster/furnace:

Manufacturer:

Type of boiler: Water tube and fire tube

Boiler manufacturer: Seattle

Type of pollution control: Water scrubber

Reason for using wood fuel: Economics

*1991 data

\section{Daishowa America}

P.O. Box 271

Port Angeles, WA 98362

Phone: (206) 457-4474

Contact: J. Boyd

Type of business: Pulp and paperboard

Type of biomass fuel: Hog fuel

Source of fuel: Purchased

Annual biomass fuel consumed: 53,000 BDUs

Back-up fuel: No. 6 fuel oil

End use(s): Process steam, drying

Plant design capacity: $1 \mathrm{Hog}$ fuel boiler

Heat (Million Btu/hr):

Steam: 105,000 lbs/hr @ 255 psig

Electrical generation (MW): None

Average plant output:

Heat (Million Btu/hr):

Steam: 75,000 lbs/hr@ 255 psig

Electrical generation (MW): None

Type of combuster/furnace: Spreader stoker

Manufacturer: Combustion Engineering

Type of boiler: Model VU-40

Boiler manufacturer: Combustion Engineering

Type of pollution control: Venturi Scrubber

Reason for using wood fuel: Economics 


\section{Fort Vancouver Plywood}

P.O. Box 289

Vancouver WA 98660

Phone: (206) 694-3368

Contact: Duane Graves

Type of business: Plywood

Type of biomass fuel: Hog fuel, sawdust

Source of fuel: In-house and purchased

Annual biomass fuel consumed: 35,000 units

Back-up fuel: None

End use(s): Process heat

Plant design capacity:

Heat (Million Btu/hr):

Steam: 75,000 lbs/hr@ 300 psig

Electrical generation (MW): None

Average plant output:

Heat (Million Btu/hr):

Steam: 45,000 lbs/hr @ 290 psig

- Electrical generation (MW): None

Type of combuster/furnace: None

Manufacturer:

Type of boiler: Hog fuel fired, water tube

Boiler manufacturer: Kipper \& Sons

Type of pollution control: Wet scrubber

Reason for using wood fuel: By-product of manufacturing

\section{Fred Tebb \& Sons, Incorporated}

1906 Marc Street

Tacoma, WA 98421

Phone: (206) 272-4107

Contact: Marlene DeMarco

Type of business: Remanufacture of lumber products

Type of biomass fuel: Sawdust

Source of fuel: In-house

Annual biomass fuel consumed: 219 tons

Back-up fuel: Natural gas, oil

End use(s): Drying of lumber

Plant design capacity:

Heat (Million Btu/hr):

Steam: 15,000 lbs/hr @ 10 psig

Electrical generation (MW):

(continued on next column)
Average plant output:

Heat (Million Btu/hr):

Steam: 15,000 lbs/hr @ 10 psig

Electrical generation (MW):

Type of combuster/furnace: Oil, gas, wood

Manufacturer: Rayburn

Type of boiler: Fire tube

Boiler manufacturer: Cleaver

Type of pollution control: Baghouse

Reason for using wood fuel: Economics

\section{Georgia-Pacific Corporation}

P.O. Box 1236

Bellingham, WA 98227

Phone: (206) 733-4410

Contact: E. H. Dahlgren

Type of business: Pulp and paper

Type of biomass fuel:

Hog fuel Source of fuel: Purchased \& generated

Annual biomass fuel consumed: 157,000 bone dry tons

Back-up fuel: Natural gas/No. 6 oil

End use(s): Process steam, drying

Plant design capacity:

Heat (Million Btu/hr): 232

Steam: 220,000 lbs/hr @ 200 psig

Electrical generation (MW): None

Average plant output:

Heat (Million Btu/hr): 185

Steam: 175,000 lbs/hr@ 175 psig

Electrical generation (MW): None

Type of Combustion/Furnace: Dutch oven boilers

Manufacturer: Babcock \& Wilcox

Type of boiler: Sterling Boiler

Manufacturer: Babcock \& Wilcox

Type of pollution control: Baghouse

Reason for using wood fuel: Economics 
Goodyear Nelson Hardwood

Lumber Company, Inc.

1215 Highway $9 S$

Sedro Woolley, WA 98284

Phone: (206) 856-0816

Contact: Rod Remington

Type of business: Hardwood lumber

Type of biomass fuel: Hog fuel and shavings

Source of fuel: Westem hardwood residue and surfacing

Annual biomass fuel consumed: $12,351 \mathrm{BDTs} / \mathrm{yr}$

Back-up fuel:

End use(s): Steam for dry kilns

Plant design capacity:

Heat (Million Btu/hr):

Steam: 25,000 lbs/hr @ 110 psig

Electrical generation (MW): N/A

Average plant output:

Heat (Million Btu/hr):

Steam: 19,500 lbs/hr @ 110 psig

Electrical generation (MW): None

Type of combuster/furnace: Auto mini-stoker system

Manufacturer: G\&S Retrofit

Type of boiler: Fire tube

Boiler manufacturer: Brownell

Type of pollution control: Brescove Regenerative Collector

Reason for using wood fuel: Availability

GN Plywood Inc.

(formerly Mt. Baker Plywood)

P.O. Box 997

Bellingham, WA 98225

Phone: (206) 733-3960

Contact: Tim Shannon

Type of business: Plywood

Type of biomass fuel: Hog fuel

Source of fuel: In-house

Annual biomass fuel consumed: 19,200 BDTs/yr

Back-up fuel: Natural gas

End use(s): Drying and pressing

Plant design capacity:

Heat (Million Btu/hr):

Steam: 35,000 lbs/hr@ @ 1,700 psig

Electrical generation (MW): None

(continued on next column)
Average plant output:

Heat (Million Btu/hr):

Steam: 31,500 Ibs/hr @ 225 psig

Electrical generation (MW):

Type of combuster/furnace: Dutch oven.

Manufacturer: Kipper

Type of boiler:

Boiler manufacturer:

Type of pollution control: Multi cyclone ash collector

Reason for using wood fuel: Economics

Guy Bennett Lumber Co.

1785 Elm Street

Clarkston, WA 99403

Phone: (509) 758-5558

Contact: Don Fairley

Type of business: Lumber

Type of biomass fuel: Hog fuel

Source of fuel: In-house

Annual biomass fuel consumed: 11,242 BDTs/yr

Back-up fuel: None

End use(s): Heat for dry kilns

Plant design capacity:

Heat (Million Btu/hr): $22,425,000$

Steam: 19,500 lbs/hr@ 100 psig

Electrical generation (MW):

Average plant output:

Heat (Million Btu/hr): $2,070,000$

Steam: 8,000 lbs/hr@ 100 psig

Electrical generation (MW):

Type of combuster/furnace: Water tube

Manufacturer: Kipper

Type of boiler: Water tube

Boiler manufacturer: Kipper

Type of pollution control: Multicone \& electric precipitator Reason for using wood fuel: Generated during manufacturing. 


\section{Hardel Mutual Plywood*}

1210 West Bay Drive

Olympia, WA 98502

Phone: (206) 754-6030

Contact: Emanuel Piliaris

Type of business: Plywood

Type of biomass fuel: Sander dust \& hog fuel

Source of fuel: In-house

Annual biomass fuel consumed: 17,977 BDTs

Back-up fuel: Natural gas

End use(s): Dryers and presses

Plant design capacity:

Heat (Million Btu/hr): 38.87

Steam: 28,000lbs/hr@ 225 psig

Electrical generation (MW):

Average plant output:

Heat (Million Btu/hr)

Steam:25,000 lbs/hr@___psig

Electrical generation (MW): N/A

Type of combuster/furnace: Suspension burner

Manufacturer: Coen

Type of boiler: Fire tube

Boiler manufacturer: Pacific Marion

Type of pollution control: Joy Multicone

Reason for using wood fuel: It is by far the most cost

effective choice: waste wood means free fuel.

*1991 Data

\section{James River}

NE Fourth \& Adams Street

Camas, WA 98607

Phone: (206) 834-8161

Contact: W. W. Vautzelfden

Type of business: Pulp and paperboard

Type of biomass fuel: Hog fuel \& mill residue

Source of fuel: Purchased

Annual biomass fuel consumed: 104,000

Back-up fuel: Gas/oil

End use(s): Process steam, dryers

Plant design capacity:

. Heat (Million Btu/hr):

Steam: 240,000 lbs/hr @ 600 psig

Electrical generation (MW): 0

(continued on next column)
Average plant output:

Heat (Million Btu/hr):

Steam: 200,000 lbs/hr@ 900 psig

Electrical generation (MW): 0

Type of combuster/furnace: Water cooled vibrating gate Manufacturer: Foster Wheeler

Type of boiler: Conventional water wall

Boiler manufacturer:

Type of pollution control: Electrostatic precipitator

Reason for using wood fuel: Available waste/low cost

*Note: Installing electrical generation, on -line in 1995.

\section{Jeld-Wen of Everett}

300 W Marine Drive

Everett, WA 98201

Phone: (206) 259-9292, ext. 123

Contact: Randy Cox

Type of business: Wood remanufacturing/lumber drying .

Type of biomass fuel: Hog fuel

Source of fuel: In-house

Annual biomass fuel consumed: 10,000 tons/year

Back-up fuel: Natural Gas

End use(s): Dry kiln and slicer tank

Plant design capacity: .

Heat (Million Btu/hr):

Steam: 55,000 lbs/hr @ 125 psig

Electrical generation (MW): None

Average plant output:

Heat (Million Btu/hr):

Steam: $15,000 \mathrm{lbs} / \mathrm{hr} @ 125 \mathrm{psig}$

Electrical generation (MW): None

Type of combuster/furnace:

Manufacturer:

Type of boiler: Water tube

Boiler manufacturer: Wyatt Kipper

Type of pollution control: Multi-clone

Reason for using wood fuel: Economics 
Jeld-Wen Fiber of Washington

Comer of Wesley \& Fort Roads

White Swan, WA 98952

Phone: (509) 874-2255

Contact: Tom Wilson

Type of business: Fiberboard doorskins

Type of biomass fuel: Wood

Source of fuel: Plant waste

Annual biomass fuel consumed: $10,000-15,000$ tons

Back-up fuel:

End use(s): Plant space heat, process heat

Plant design capacity:

Heat (Million Btu/hr):

Steam: 30,000 lbs/hr @ 200 psig

Electrical generation (MW): None

Average plant output:

Heat (Million Btu/hr):

Steam: 13,000 - 17,000 lbs/hr @ 200 psig

Electrical generation (MW): None

Type of combuster/furnace: 2 cell forced draft

Manufacturer: Wellons

Type of boiler: Water tube

Boiler manufacturer: Nebraska

Type of pollution control: Mechanical, multi-cone scrubber

Reason for using wood fuel: Availability of wood waste

\section{Kinnear of Washington}

2001 Industrial Drive

Centralia, WA 98531

Phone: (206) 736-7651

Contact: Greg Penley

Type of business: Wood parts for overhead garage doors

Type of biomass fuel: Mill residues

Source of fuel: In-house

Annual biomass fuel consumed: 1,100 tons

Back-up fuel: None

End use(s): Drying lumber

Plant design capacity:

Heat (Million Btu/hr): Unknown

Steam: $10,300 \mathrm{lbs} / \mathrm{hr} @ 100$ psig

Electrical generation (MW): None

(continued on next column)
Average plant output:

Heat (Million Btu/hr): Unknown

Steam: 8,250 lbs/hr@ 80 psig

Electrical generation (MW): None

Type of combuster/furnace: Firebox

Manufacturer: Frye Shaving Feeder

Type of boiler: Fire tube

Boiler manufacturer: Kewanee $\# 590$

Type of pollution control: Wet scrubber

Reason for using wood fuel: Available/low cost

K-Ply, Inc.

439 Marine Drive

Port Angeles, WA 98362

Phone: (206) 457-4421

Contact: Dave Mackey

Type of business: Plywood

Type of biomass fuel: In-house

Source of fuel: Bark, veneer trim, plywood trim

Annual biomass fuel consumed: 24,000 BDTs (estimate)

'Back-up fuel: None

End use(s): Drying, veneer

Plant design capacity:

Heat (Million Btu/hr):

Steam: 50,000 lbs/hr @ 240 psig

( 2 boilers $25,000 \mathrm{hr}$ ea.)

Electrical generation (MW): None

Average plant output:

Heat (Million Btu/hr):

Steam: 40,000 lbs/hr @ 240 psig

Electrical generation (MW): None

Type of combuster/furnace:

Manufacturer: Riley

Type of boiler:

Boiler manufacturer: Riley

Type of pollution control: Wet E.S.P.

Reason for using wood fuel: Availability 


\section{Layman's Lumber Company}

11160 Highway 12

Naches, WA 98937

Phone: (509) 653-2221

Contact: George Layman

Type of business: Lumber

Type of biomass fuel: Hog fuel

Source of fuel: In-house

Annual biomass fuel consumed: 3,000 tons

Back-up fuel:

End use(s): Dry kilns

Plant design capacity: Heat (Million Btu/hr):

Steam: 17,250 lbs/hr@ @ 15 psig

Electrical generation (MW):

Average plant output:

Heat (Million Btu/hr):

Steam: 15,000 lbs/hr@ 15 psig

Electrical generation (MW):

Type of combuster/furnace:

Manufacturer: Wellons

Type of boiler: Fire tube

Boiler manufacturer:

Type of pollution control: Recycle

Reason for using wood fuel:

\section{Longview Fibre Company}

P.O. Box 3000

Longview, WA 98632

Phone: (206) 425-1550

Contact: R. W. Williams

Type of business: Pulp and paperboard

Type of biomass fuel: Hog fuel

Source of fuel: Purchased

Annual biomass fuel consumed: 130,296 dry tons

Back-up fuel: Fuel oil, natural gas

End use(s): Process steam, dryers

Plant design capacity: 3 Hog fuel boilers

Heat (Million Btu/hr): 1,160

Steam: 850,000 lbs/hr @ 800 psig

(2 boilers @ 275,000, 1 boiler@ 300,000)

Electrical generation (MW): 30 (hog fuel portion)

(continued on next column)
Average plant output: Calendar 1993 (hog fuel $27 \%$ fuel used in above boilers)

Heat (Million Btu/hr): 153 (hog fuel portion)

696 total

Steam: 113,645 lbs/hr@800 psig

(hog fuel portion)

Electrical generation (MW): 13 (hog fuel portion)

Type of combuster/furnace: N/A

Manufacturer: N/A

Type of boiler: 2 Dutch ovens, 1 Stoker- Traveling Grate

Boiler manufacturer. 2 Babcock \& Wilson,

1 Combustion Engineering

Type of pollution control: Multicone \& wet scrubbers

Reason for using wood fuel: Lowest cost fuel

\section{Louisiana Pacific Company}

P.O. Box 1575

Walla Walla, WA 98362

Phone: (509) 529-0200

Contact: Jerry Doherty

Type of business: Lumber

Type of biomass fuel: Hog fuel

Source of fuel: In-house

Annual biomass fuel consumed: 6,563 BDTs

Back-up fuel:

End use(s): Dry kilns

Plant design capacity:

Heat (Million Btu/hr): $21,000,000$

Steam: 20 to 25,000 lbs/hr @____psig

Electrical generation (MW): None

Average plant output:

Heat (Million Btu/hr): $14,060,000$

Steam: 13,400 lbs/hr@___psig

Electrical generation (MW): None

Type of combuster/furnace:

Manufacturer: Seattle Boiler Works

Type of boiler: Dutch oven 84-20 hrt 125 lbs.

Boiler manufacturer: Seattle Boiler Works

Type of pollution control: Proper fuel \& air ratio

Reason for using wood fuel: Cost 


\section{Morton Forest Products}

\section{Priest Road}

\section{P.O. Box I}

Morton, Washington 98356

Phone: (206) 496-6666

\section{Contact: Don Schroeder}

Type of business: Lumber, veneer

Type of biomass fuel: Hog fuel

Source of fuel: In-house

Annual biomass fuel consumed: 11,435 dry-units

Back-up fuel: None

End use(s): Dry kilns, hot water vats

Plant design capacity: 20,000

Heat (Million Btu/hr): 23.1

Steam: 20,000 lbs/hr @ 125 psig

Electrical generation (MW): None

Average plant output:

Heat (Million Btu/hr): 21.2

Steam: 18,333 lbs/hr@ 125 psig

Electrical generation (MW): None

Type of combuster/furnace: Dutch oven

Manufacturer: Zinda

Type of boiler: Double drum, water tube, type RO

Boiler manufacturer: Riley

Type of pollution control: Ash separator,

Lear Sigler Monitor

Reason for using wood fuel: Economics

\section{Northwest Hardwoods}

20015 - 67th NE

(mailing - P.O. Box 7)

Arlington, WA 98223

Phone: (206) 435-8502

Contact: Dennis Thompson

Type of business: Lumber

Type of biomass fuel: Sander dust

Source of fuel: In-house

Annual biomass fuiel consumed: Unknown

Back-up fuel: Natural gas

End use(s): Dry kilns

Plant design capacity:

Heat (Million Btu/hr):

Steam: 18,000 lbs/hr @ 22 psig

Electrical generation (MW):

(continued on next column)
Average plant output:

Heat (Million Btu/hr):

Steam: 18,000 lbs/hr @ 22 psig

Electrical generation (MW):

Type of combusster/furnace:

Manufacturer:

Type of boiler: Fire tube

Boiler manufacturer: Cleaver Brooks

Type of pollution control: 3 cell bag house

Reason for using wood fuel: It is produced in our lumber finishing process

Oeser Company, The

730 Marine Drive

Bellingham, WA 98225

Phone: (206) 734-1480

Contact: Ronald S. Durbin, Plant Manager

Type of business: Wood treating

Type of biomass fuel: Hog fuel

Source of fuel: In-house

Annual biomass fuel consumed: 400 tons (est.)

Back-up fuel: Natural gas

End use(s): Steam heat for treating processes

Plant design capacity:

Heat (Million Btu/hr): 250 - $400 \mathrm{bhp}$

Steam: ___ lbs/hr@ 120 psig

Electrical generation (MW): None

Average plant output:

Heat (Million Btu/hr): $150 \mathrm{bhp}$

Steam: ____lbs/hr@120 psig

Electrical generation (MW): None

Type of Combuster Furnace: Dutch oven

Manufacturer: Constructed on sight by plant personnel

Type of boiler: Water tube

Boiler manufacturer: Sterling

Type of pollution control: Visual at stack/mix w/natural gas

Reason for using wood fuel: It is a manufacturing byproduct, economical, a reliable supply, and otherwise wasted if not used for fuel 
Omak Wood Products, Incorporated

Route 2, Box 54

Omak, WA 98841.

Phone: (509) 826-1460, ext. 238

Contact: Jerry Gregerson

Type of business: Lumber and plywood

Type of biomass fuel: Hog fuel, sawdust

Source of fuel: In-house \& purchased

Annual biomass fuel consumed: 175,200 dry units

Back-up fuel: Natural gas

End use(s): Dry kilns and veneer presses, power generation

Plant design capacity:

Heat (Million Btu/hr):

Steam: 240,000 lbs/hr @ 675 psig)

Electrical generation (MW): 7.5

Average plant output:

Heat (Million Btu/hr):

Steam: $160,000 \mathrm{lbs} / \mathrm{hr} @ 600 \mathrm{psig}$

Electrical generation (MW): 7.5

Type of combuster/furnace: 2 air suspension type burners

Manufacturer: Riley Boiler

Type of boiler: Water tube

Boiler manufacturer: Riley Stoker, 2 units

Type of pollution control: Wet scrubber

Reason for using wood fuel: By-product of production, disposes production residues.

Plum Creek Manufacturing, L.P. Inc.

Arden Lumber Operations

634 Highway $395 \mathrm{~S}$

Colville, WA 99114

Phone: (509) 684-7738

Contact: John Chopot

Type of business: Lumber

Type of biomass fuel: Hog fuel

Source of fuel: In-house, sawmill

Annual biomass fuel consumed: 23,937 BDTs

Back-up fuel: Natural gas

End use(s): Dry kilns, space heat

Plant design capacity:

Heat (Million Btu/hr):

Steam: 40,000 lbs/hr @ 150 psig

Electrical generation (MW): None

(continued on next column)
Average plant output:

Heat (Million Btu/hr):

Steam: 32,000 lbs/hr@ 125 psig

. Electrical generation (MW): None

Type of Combustion/Furnace:

Manufacturer:

Type of boiler: Single cell

Boiler manufacturer: Kipper \& Son

Type of pollution control: Electrostatic precipitator

Reason for using wood fuel: Availability, cost

\section{Port Townsend Paper}

P.O. Box 3170

Port Townsend, WA 98368

Phone: (206) 385-3170 ext. 202

Contact: Bruce McComas

Type of business: Pulp and paper

Type of biomass fuel: Hog fuel

Source of fuel: Purchased .

Annual biomass fuel consumed: 64,217 dry tons

Back-up fuel: Residual oil

End use(s): Process steam and dryers

Plant design capacity: 2 Hog fuel

Heat (Million Btu/hr):

Steam: 250,000 lbs/hr̈ @ 600 psig

Electrical generation (MW): 18.5

Average plant output:

Heat (Million Btu/hr):

Steam: 133,000 lbs/hr @ 400 psig

Electrical generation (MW): 6.1

Type of combuster/furnace:

Manufacturer: Combustion Engineering

Type of boiler: VU 40

Boiler manufacturer:

Type of pollution control: Mechanical collectors, plus wet scrubbers

Reason for using wood fuel: Cost 


\section{Rayonier, Incorporated}

(formerly ITT Rayonier)

700 N. Ennis Street

Port Angeles, WA 98362-0030

Phone: (206) 457-3391

Contact: Don C. Robertson

Type of business: Pulp

Type of biomass fuel: Hog fuel, primary \& sec. sludge mix Source of fuel: In-house and purchased and produced

Annual biomass fuel consumed: 89,425 BDTs (metric)

Back-up fuel: fuel oil

End use(s): Process steam, dryers

Plant design capacity:

Heat (Million Btu/hr): 290

Steam: 200,000 lbs/hr@ @ 425 psig

Electrical generation (MW): 12.0

Average plant output:

Heat (Million Btu/hr): 254

Steam:___ lbs/hr @ 425 psig

Electrical generation (MW): 1.6

Type of combuster/furnace: Hog fuel

Manufacturer: Bumstead-Woolford

Type of boiler: Pin hole stationary grate

Boiler manufacturer: Riley

Type of pollution control: Barron Cinder collectors and combustion power gravel scrubbers

Reason for using wood fuel: By-product of pulp production

\section{Scott Paper}

2600 Federal Avenue

Everett, WA 98220

Phone: (206) 259-7333

Contact: Alex M. Hood

Type of business: Pulp and paper

Type of biomass fuel: Hog fuel

Source of fuel: Purchased and.in-house

Annual biomass fuel consumed: 140,000 units

Back-up fuel: \#6 oil

End use(s): Process steam, drying

Plant design capacity: 11 boilers (5 are hog fuel)

Heat (Million Btu/hr):

Steam: $5 @ 50,000$ lbs/hr @ 225 psig

(hog fuel), $1 @ 120,000 \mathrm{lbs} / \mathrm{hr}$,

$3 @ 150,000 \mathrm{lbs} / \mathrm{hr}$,

$1 @ 380,000$ lbs/hr

Electrical generation (MW): None

(continued on next column)
Average plant output:

Heat (Million Btu/hr): 820

Steam: 650,000 lbs/hr @ 225 \& 300 psig

Electrical generation (MW): None

Type of combuster/furnace: Dutch oven

Manufacturer: Puget Sound Machinery Depot, B\&W

Modification

Type of boiler: 4 drum Stirling

Boiler manufacturer: Same as above

Type of pollution control: Baghouse

Reason for using wood fuel: Economics

\author{
Simpson Door Company \\ McCleary Operations \\ McCleary, WA 98557 \\ Phone: (206) 495-3291 \\ Contact: Robert K. Horton
}

Type of business: Doors

Type of biomass fuel: Mill residue

Source of fuel: In-house

Annual biomass fuel consumed: 18,000 dry units

Back-up fuel: Purchased hog fuel

End use(s): Steam for wood drying and heating

Plant design capacity:

Heat (Million Btu/hr): N/A

Steam 45,000 lbs/hr@ 250 psig:

Electrical generation (MW): None

Average plant output:

Heat (Million Btu/hr): N/A

Steam: 25,000 lbs/hr@150 psig

Electrical generation (MW): None

Type of combuster/furnace: Dutch oven

Manufacturer: Batènhauser

Type of boiler: Water tube -3 pass

Boiler manufacturer: Batenhauser

Type of pollution control: All dry fuel - baghouses

on fuel handling

Reason for using wood fuel: By product of manufacturing doors 


\section{Simpson Tacoma Kraft Company}

801 Portland Avenue

Tacoma, WA 98421

Phone: (206) 572-2150 or 596-0257

Contact: David McEntee

Type of business: Pulp and paper

Type of biomass fuel: Hog fuel

Source of fuel: Purchased

Annual biomass fuel consumed: 174,000 BDTs

Back-up fuel: Bunker C \& natural gas

End use(s): Process steam, dryers

Plant design capacity: 1 Hog fuel

Heat (Million Btu/hr): 254

Steam: 225,000 lbs/hr@ 425 psig

Electrical generation (MW): None

Average plant output:

Heat (Million Btu/hr): 231,000

Steam: 205,000 lbs/hr @ 425 psig

Electrical generation (MW): None

Type of combuster/furnace: Distributor/Detroit

Hydro-Grate

Manufacturer: Detroit, Stoker

Type of boiler: 2 drum natural circulation

Boiler manufacturer: Riley

Type of pollution control: Electro static precipitator

Reason for using wood fuel: Economics

\section{Simpson Timber Company \\ Waterfront Street \\ Shelton, WA 98584 \\ Phone: (206) 426-3381 \\ Contact: Jenny Soehnlein}

Type of business: Lumber and Plywood

Type of biomass fuel: Hog fuel

Source of fuel: In-house

Annual biomass fuel consumed: $89,000 \mathrm{BDTs}$

Back-up fuel: None

End use(s): Drying, lumber and plywood veneers

Plant design capacity: 6 fuel cells

Heat (Million Btu/hr): 140 approx.

Steam: 140,000 lbs/hr@ 300 psig

Electrical generation (MW): None

(continued on next column)
Average plant output:

Heat (Million Btu/hr): 130 approx.

Steam: 125,000 lbs/hr @ 300 psig

Electrical generation (MW): None

Type of combuster/furnace: Fuel cell

Manufacturer: Wellons

Type of boiler: Water tube

Boiler manufacturer: Wellons

Type of pollution control: Two stage combustion plus multicones and electrostatic precipitators

Reason for using wood fuel: Lowest cost, in-house fuel

\section{Smith Street Mill, Incorporated ${ }^{*}$}

3600 Smith Street

Everett, WA 98201

Phone: (206) 252-7179

Contact: Bob Buse

Type of business: Alder sawmill and planning mill

Type of biomass fuel: Alder sawdust and dry shavings

Source of fuel: Sawmill

Annual biomass fuel consumed:

Back-up fuel: None

End use(s): Heat dry kilns

Plant design capacity:

Heat (Million Btu/hr):

Steam: ___ lbs/hr@ $15 \mathrm{psig}$

Electrical generation (MW): None

Average plant output:

Heat (Million Btu/hr):

Steam: __ lbs/hr@ $15 \mathrm{psig}$

Electrical generation (MW): None

Type of combuster/furnace: Dutch oven

Manufacturer: In-house

Type of boiler: Low pressure, $2015 \mathrm{lbs}$.

Boiler manufacturer: Brownell ${ }^{\circ}$

Type of pollution control:

Reason for using wood fuel: Economics

*1991 Data 


\section{Strauser Manufacturing Company}

\section{$3301 \mathrm{E}$. Isaacs}

Walla Walla, Washington 99362

Phone: (509) 529-6284

Contact: Beverly Strauser

Type of business: Wood products mfg.

Type of biomass fuel: Hogfuel, sawdust, shavings

Back-up fuel:

Source of fuel: In-house

Annual biomass fuel consumed: 3,000 dry tons

End use(s): Space and process heat

Plant design capacity:

Heat (Million Btu/hr:

Steam:6,000 lbs/hr @ 250psig

Electrical generation (MW):

Average plant output:

Heat (Million Btu/hr):

Steam: 4,800 lbs @___psig

Electrical generation (MW):

Type of combuster/furnace: Suspension gasifier

Combuster/furnace manufacturer:

Type of boiler: $250 \mathrm{hp}$ Cleaver Brooks

Boiler manufacturer:

Type of pollution control: Flash collector

Reason for Use: Economics

\section{Summit Timber Power House}

29917 Bennittville Store Road

Darrington, WA 98241

Phone: (206) 259-4185, ext. 121

Contact: Ed McDaniel, Power House Sup.

Type of business: Wood products

Type of biomass fuel: Hog fuel

Source of fuel: In-house

Annual biomass fuel consumed: 36,500 dry tons

Back-up fuel: Bunker C Fossil (oil)

End use(s):

Plant design capacity:

Heat (Million Btu/hr):

Steam: 45,000 lbs/hr@ 150 psig

Electrical generation (MW): None

(continued on next column)
Average plant output:

Heat (Million Btu/hr):

Steam: lbs/hr@ psig

Electrical generation (MW): None

Type of combuster/furnace:

Combuster/Furnace manufacturer: Puget Sound Boiler

Type of boiler: Water tube

Boiler manufacturer:

Type of pollution control: Breslove Separator

Reason for using wood fuel: Cost, incinerate wood waste

Tacoma Steam Plant No. 2

Tacoma City Light

P.O. Box 11007

Tacoma, WA 98411

Phone: (206) 502-8324

Contact: Barbara Serr

Type of business: Electric power generation

Type of biomass fuel: Hog fuel, RDF, and coal

Source of fuel: Local area

Annual biomass fuel consumed: 354,200 tons

Back-up fuel: Coal

End use(s): Electricity

Plant design capacity: 820 tons per day

Heat (Million Btu/hr): $831 \mathrm{RDF} /$ wood/coal

Steam:

Electrical generation: $43 \mathrm{MW}$

Average plant output: 820 tons per day

Heat (Million Btu/hr):

Steam:

Electrical generation: $43 \mathrm{MW}$

Type of Combustion/Furnace: Fluidized bed

Manufacturer: Energy Products of Idaho

Type of boiler:

Boiler manufacturer:

Type of pollution control: Limestone in bed, baghouses

Reason for using wood fuel: Economics 


\section{Vaagen Brothers Lumber Company}

(formerly San Poil Lumber Company)

P.O. Box 357

Republic, WA 99166

Phone: (509) 775-3346

Contact: Dave Scott

Type of business: Lumber

Type of biomass fuel: Hog fuel

Source of fuel: In-house

Annual biomass fuel consumed: 25,000 units

Back-up fuel:

End use(s): Dry kiln

Plant design capacity:

Heat (Million Btu/hr):

Steam: 50,000 lbs/hr @ 150 psig

Electrical generation (MW):

Average plant output:

Heat (Million Btu/hr):

Steam: 30,000 lbs/hr @ 150 psig

Electrical generation (MW):

Type of combuster/furnace: 1D-FD

Manufacturer: Wellons

Type of boiler: Woodwaste fired (bark, etc.)

Boiler manufacturer: Nebraska

Type of pollution control: 8 - $10 \mathrm{CO} 2$ Multicone collector

Reason for using wood fuel: Availability

\section{Vaagen Brothers Lumber, Incorporated \\ 565 W Fifth}

Colville, WA 99114

Phone: (509) 684-5071

Contact: Gene Sackman, Supt.

Type of business: Lumber

Type of biomass fuel: Hog fuel

Source of fuel: In-house

Annual biomass fuel consumed: 25,550 tons

Back-up fuel: No

End use(s): Dry kilns, generator

Plant design capacity:

Heat (Million Btu/hr):

Steam: 60,000 lbs/hr @ 510 psig

Electrical generation (MW): $4,000 \mathrm{~kW}$

(continued on next column)
Average plant output:

Heat (Million Btu/hr):

Steam: 60,000 lbs/hr @ 510 psig

Electrical generation (MW): $4,000 \mathrm{~kW}$

Type of combuster/furnace: Fuel cell 4 cells

Manufacturer: Wellons

Type of boiler: Water tube

Boiler manufacturer: Nebraska

Type of pollution control: Mulitcones

Reason for using wood fuel: Economics

Vaagen Brothers Lumber, Inc.

P.O. Box 257

Ione, WA 99139

Phone: (509) 442-3511

Contact: Don Curry, Plant Manager

Type of business: Lumber

Type of biomass fuel: Hog fuel

Source of fuel: In-house

Annual biomass fuel consumed: 9,490 tons

Back-up fuel:

End use(s): Dry kilns

Plant design capacity:

Heat (Million Btu/hr): 12.5

Steam: 40,000 lbs/hr@150psig

Electrical generation (MW):

Average plant output:

Heat (Million Btu/hr):

Steam: 30,000 lbs/hr@150 psig

Electrical generation MW):

Type of combuster/furnace: Radiant furn. heating surface

Manufacturer: Wellons

Type of boiler: Water tube

Boiler manufacturer: Nebraska Boiler Company

Type of pollution control: Multicones

Reason for using wood fuel: Cost efficient 
W.I. Forest Products*

(also, Crown - Pacific Inland)

2302 E Mallon

Spokane, WA 99202

Phone: (509) 534-1561

Contact: Tom Landwehr

Type of business: Lumber

Type of biomass fuel: Hog fuel

Source of fuel: In-house

Annual biomass fuel consumed: Unknown

Back-up fuel: Natural gas

End use(s): Dry kilns

Plant design capacity:

Heat (Million Btu/hr):

Steam: 30,000 lbs/hr@ 125 psig

Electrical generation (MW): None

Average plant output:

Heat (Million Btu/hr):

Steam: 30,000 lbs/hr @ 125 psig

Electrical generation (MW): None

Type of combuster/furnace:

Manufacturer: Combustion Engineering

Type of boiler: Sterling 3-drum water tube.

Boiler manufacturer: Combustion Engineering

Type of pollution control: Mechanical Fabricators baghouse

Reason for using wood fuel: Inexpensive, readily available

*1991 data

\section{West Coast Forest Products; Inc.}

19406 68th Drive NE

P.O. Box 365

Arlington, WA 98223

Phone: (206) 435-2175

Contact: Jim Reece or Gary Erickson

Type of business: Lumber remanufacturer

Type of biomass fuel: Shavings

Source of fuel: Planer

Annual biomass fuel consumed: 4,720 Dry tons

Back-up fuel: None

End use(s): Dry kilns

Plant design capacity:

Heat (Million Btu/hr): 22.5

Steam:___ lbs/hr @___psig

Electrical generation (MW): N/A

(continued on next column)
Average plant output:

Heat (Million Btu/hr):

Steam:___lbs/hr@ 100 psig

Electrical generation (MW): None

Type of combuster/furnace:

Manufacturer:

Type of boiler: Fire tube

Boiler manufacturer: Titusville

Type of pollution control: Mikropul Baghouse

Reason for using wood fuel: Cost and availability

\section{Weyerhaeuser Company}

P.O. Box 1000

Cosmopolis, WA 98537

Phone: (206) 532-7110

Contact: Paul W. Kelso, P\&R Manager

Type of business: Pulp .

Type of biomass fuel: Hog fuel

Source of fuel: Purchased \& in-house generated

Annual biomass fuel consumed: 80,000 BDTs

Back-up fuel: No. 6 fuel oil

End use(s): Process steam

Plant design capacity:

Heat (Million Btu/hr): 220

Steam: 160,000 lbs/hr@ @ 850 psig

Electrical generation (MW): 15.0

Average plant output:

Heat (Million Btu/hr): 138

Steam: 100,000 lbs/hr @ 850 psig

Electrical generation (MW): 11

Type of combuster/furnace: Fixed, water cooled, pin hole grate

Manufacturer: Babcox \& Wilcox

Type of boiler: Two Drum Sterling

Boiler manufacturer: Babcox \& Wilcox

Type of pollution control: Venturi wet scrubber

\& multicones

Reason for using wood fuel: By-product of company, cost 


\section{Weyerhaeuser Company}

\section{P.O. Box 188}

Longview, WA 98632

Phone: (206) 425-2150, ext. 5486

Contact: Jeff Inman

Type of business: Pulp and paperboard

Type of biomass fuel: Hog fuel, clarifier \& newsprint sludges

Source of fuel: Purchased and in-house

Annual biomass fuel consumed: 500,000 BDTs

Back-up fuel: Coal, oil, natural gas

End use(s): Process steam, dryers

Plant design capacity: 7 Hog fuel

Heat (Million Btu/hr): 1,180

Steam: 550,000 lbs/hr@ @ 1,250 psi

\& 300,000 lbs/hr@300 psi

Electrical generation (MW): 30 (hog fuel portion of total)

Average plant output:

Heat (Million Btu/hr): 1,000

Steam: 500,000 lbs/hr @ 1,250 psi \&

200,000 lbs/hr@300psi

Electrical generation (MW): 30

Type of combuster/furnace:

Manufacturer: 6 Erie City, 1 Foster Wheeler

Type of boiler: Erie City Fixed Grate, Foster Wheeler

Traveling Grate

Boiler manufacturer:

Type of pollution control: Wet scrubber, electrostatic precipitator

Reason for using wood fuel: By-product of company mills

\section{Weyerhaeuser Company}

51 Ellis Street

Raymond, WA 98577

Phone: (206) 942-2442

Contact: Jerry Dillayou, Plant Engineer

Type of business: Lumber

Type of biomass fuel: Hog fuel

Source of fuel: In-house and purchased

Annual biomass fuel consumed:

Back-up fuel: Propane used to preheat on cold start-up

End use(s): Dry kilns

Plant design capacity:

Heat (Million Btu/hr): 70,000,000

(reduced to $55 \mathrm{MM} \mathrm{Btu/hr}$ )

Steam: 50,000 lbs/hr@ 200 psig

Electrical generation (MW): None
Average plant output:

Heat (Million Btu/hr): 40,000,000 est.

Steam: 40,000 lbs/hr@ 200 psig

Electrical generation (MW): None

Type of combuster/furmace:

Manufacturer: EPI $18 \mathrm{ft}$. dia. fluid bed burner (reduced to $16 \mathrm{ft}$. dia.) built in 1974

Type of boiler: Combustion Engineering water tube boiler

Boiler manufacturer:

Type of pollution control: Zum multiclone

Reason for using wood fuel: Cost residual of lumber plant operation

\section{Weyerhaeuser Company}

7001 - 396th Street SE

Snoqualmie Falls, WA 98065

Phone: (206) 888-2511

Contact: Don MacBean, Powerhouse Manager

Type of business: Lumber

Type of biomass fuel: Hog fuel

Source of fuel: In-house and purchased

Annual biomass fuel consumed:

Back-up fuel: None

End use(s): Dry kilns

Plant design capacity: 2 boilers, $270,000 \mathrm{ppH}$. saturated

Steam total

Heat (Million Btu/hr):

Steam: 270,000 lbs/hr @___psig

Electrical generation (MW): None

Average plant output:

Heat (Million Btu/hr): $247,800 \mathrm{Btu}$

both boilers

Steam: 128,000 lbs/hr @___psig (both boilers)

Electrical generation (MW): None

Type of combuster/furnace: Dutch oven and spreader stocker

Manufacturer: One 1969 F.E. Riley $250 \mathrm{lbs}$ sat. Steam $150,000 \mathrm{ppH}$, one 1930 F.E., PSMD-155 lb sat. steam $120,000 \mathrm{ppH}$

Type of boiler: Water tube

Boiler manufacturer. Riley

Type of pollution control: AirPol, Inc. Venturi, Wet scrubber

Reason for using wood fuel: By-product

(continued on next column) 


\section{OTHER WOOD COMBUSTION FACILITIES}

\author{
DeGoede Bulb Farms \\ 409 Mossyrock Road, W \\ Mossyrock, WA 98564 \\ Phone: (206) 983-3773 \\ Contact: Bob DeGoede
}

Type of Business: Greenhouse and nursery

Type of Biomass Fuel: Mill residue

Source of Fuel: Purchased

Annual Biomass Fuel Consumed: Approx. 65 truck

loads (45 vans)

Back-up Fuel: Propane forced air unit heaters

End Use(s): Greenhouse heating

Plant Design Capacity:

Heat (million Btu/hr): 4,500,000 (depending on

fuel moisture content)

Steam (lb/hr@ @sig): N/A

Electrical Generation (MW): N/A

Average Plant Output:

Heat (million Btu/hr): 3,000,000 Btu/hr

Steam (lb/hr@_psig): N/A

Electrical Generation (MW): N/A

Type of Combustor/Fumace: Bio-Combustor

(gasification process)

Manufacturer: Bio-Mass Burner

Type of Boiler: Hot water - 210øF

Boiler Manufacturer: Vaagen Timber Products

Type of Pollution Control: Gasification/cyclone

Reason for Using Wood Fuel: Less cost

\section{Shelton Corrections Center}

P.O. Box 900

Shelton, WA 98584

Phone: (206) 426-443, ext 269

Contact: Charlie Hicks

Type of Business: State institution

Type of Biomass Fuel: Wood pellets

Source of Fuel: Purchased from Manke Lumber

Annual Biomass Fuel Consumed: 7,974.5 bdts

Back-up Fuel: none

End Use(s): Space heat, laundry, kitchen

Plant Design Capacity: 3 boiler

Heat (million Btu/hr):

Steam: 60,000 lb/hr @ 110psig

Electrical Generation (MW): None
Average Plant Output:

Heat (million Btu/hr):

Steam: 16,165lb/hr@ 110 psig

Electrical Generation (MW): None

Type of Combustor/Furnace: stoker

Manufacturer: Babcock and Wilcox

Type of Boiler: Water tube

Boiler Manufacturer: C.C. Moore \& Co. Engineers

Type of Pollution Control: multiclones

Reason for Using Wood Fuel: Emissions problems with coal.

\section{Washington Soldiers Home \& Colony}

P.O. Box 500

Orting, WA 98360

Phone: (206) 593-2045

Contact: Robert Boyce

Type of Business: Service

Type of Biomass Fuel: Wood pellets

Source of Fuel: Purchased

Annual Biomass Fuel Consumed: 100 bdts (back-up)

Back-up Fuel: Biomass (natural gas - primary fuel)

End Use(s): Space heat and hot water

Plant Design Capacity:

Heat (million Btu/hr):

Steam: 24,500 lbs/hr@ 100 psig

Electrical Generation (MW): None

Average Plant Output:

Heat (million Btu/hr):

Steam: $3,000 \mathrm{lbs} / \mathrm{hr}$

Electrical Generation (MW): none

Type of Combustor/Furnace: Spreader-Stoker

Manufacturer: Wyatt \& Kipper and ONB Tri-Fuel

Type of Boiler: Water tube and fire tube

Boiler Manufacturer:

Type of Pollution Control: Cyclone

Reason for Using Wood Fuel: Natural gas curltrilment

(continued on next column) 


\section{Washington State Penitentiary}

P.O. Box 520

Walla Walla, WA 99362

Phone: (509) 525-3610

Contact: Joe Waiblinger, Plant Mgr.

Type of Business: State Penitentiary

Type of Biomass Fuel: Wood Pellets (back-up fuel)

Source of Fuel: Purchased, Lignetics of Idaho

Annual Biomass Fuel Consumed: 1,600 dry tons

Back-up Fuel: Natural gas (primary fuel)

End Use(s): space heat, laundry, kitchen

Plant Design Capacity: 3 boilers

Heat (million Btu/hr):

Steam (lb/hr@125 psig): 75,000

Electrical Generation (MW): None

Average Plant Output:

Heat (million Btu/hr)

Steam (lb/hr @ 125 psig): 32,000 Oct. - Apr;

10,000 May - Sept.

Electrical Generation (MW): None

Type of Combustor/Furnace: Spreader stoker with pad type grates

Manufacturer: Hoffman Combustion Engineering

Type of Boiler: D type water tube

Boiler Manufacturer: Wyatt Kipper

Type of Pollution Control: Multi-clones

Reason for Using Wood Fuel: Back-up fuel source for interuptable gas. Emissions problems with coal.

\section{Washington Water Power Company}

Kettle' Falls, WA 99141

Phone: (509) 738-2449

Contact: Dale Snyder

Type of Business: Electric Utility

Type of Biomass Fuel: Hog fuel

Source of Fuel: Purchased mill residue

Annual Biomass Fuel Consumed: 500,000 green tons

Back-up Fuel: Natural gas

End Use(s): Electrical generation

Plant Design Capacity:

Heat (million Btu/hr): N/A

Steam (Ib/hr @ 1,500 psig): 415,000

Electrical Generation (MW): 48 gross

Average Plant Output:

Heat (million Btu/hr): N/A

Steam (lb/hr@ 1,525 psig): 435,000

Electrical Generation (MW): 50.3

(continued on next column)
Type of Combustor/Furnace: Spreader stoker, moving grate

Manufacturer: Combustion Engineering

Type of Boiler: Water tubeBoiler

Manufacturer: Combustion Engineering .

Type of Pollution Control: ESP and mechanical

collector

Reason for Using Wood Fuel: Availability

\section{Western State Hospital}

P.O. Box 94999

Fort Steilacoom, WA 98494

Phone: (206) 756-2519

Contact: Ronald Hansen

Type of Business: State Hospital

Type of Biomass Fuel: Wood Pellets

Source of Fuel: Purchased, Eureka Pellet Mills

Annual Biomass Fuel Consumed: 750 - 1,000 bdts

Back-up Fuel: Natural gas

End Use(s): Back-up fuel

Plant Design Capacity: 3 boilers

Heat (million Btu/hr):

Steam (lb/hr @ 110 psig): 23,000;

60,000; 210,000

Electrical Generation (MW): None

Average Plant Output:

Heat (million Btu/hr):

Steam (lb/hr@ 110 psig): 23,000;

60,$000 ; 210,000$

Electrical Generation (MW): None

Type of Combustor/Furnace: Stoker feed peletized

Manufacturer: Hoffman

Type of Boiler: Water tube

Boiler Manufacturer: Garet \& Shater; Wyatt-Kipper;

Puget Sound Machine

Type of Pollution Control: Oxygen \& $\mathrm{CO} 2$ monitor

Reason for Using Wood Fuel: Emissions problems with coal 


\section{Waste Wood Combustion Facilities Listing Changes from 1992 Edition}

Name Changes

County

New Name

GN Plywood Inc.

Rayonier, Incorporated .

Vaagen Brothers Lumber Co.

Crown - Pacific Inland

Kroon, Inc.

\section{Old Name}

Mt. Baker Plywood

ITT Rayonier, Inc.

San Poil Lumber Company

Also using, W.I. Forest Products

Also using, Coastcraft, Inc.
Whatcom

Clallam

Ferry

Spokane

Pierce

\section{Additions}

No new additions.

\section{Deletions}

ITT Rayonier, Inc. - Grays Harbor

Pacific Wood Treating

Puget Sound Plywood

Stevenson Co-Ply, Incorporated

\section{Cause}

Division closed. Boilers sold to Grays Harbor Paper. L.P.

Out of business

Out of business

Out of business

\section{County}

Grays Harbor

Clark .

Pierce

Skamania 


\section{Chapter 3}

Ethanol Production 


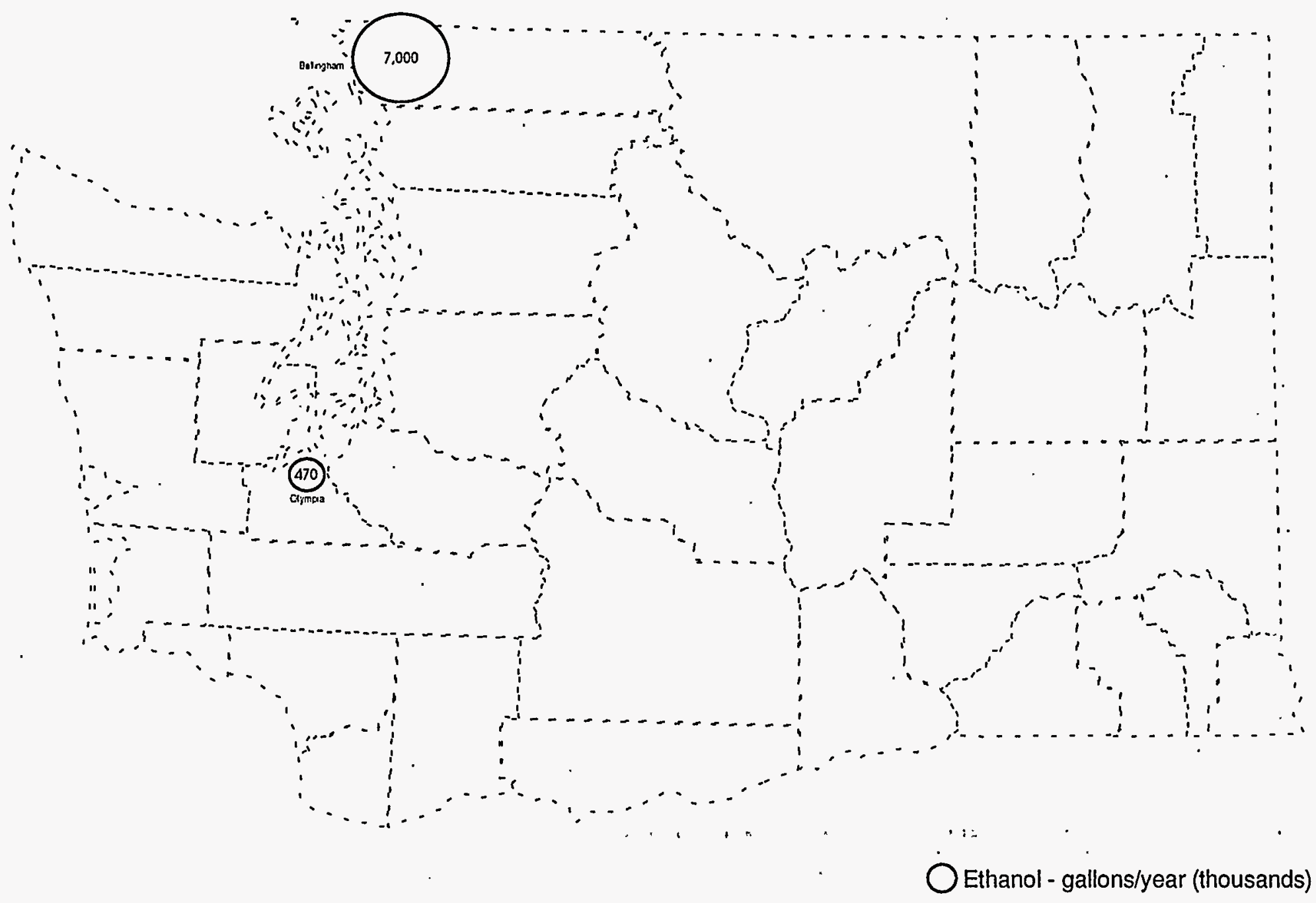

Figure 7

1993 Washington State Ethanol Production

Source: WSEO, 1994 Washington State Directory of Biomass Energy Facilities 
Table 8

1993 Ethanol Production

Sorted by Average Ethanol Output

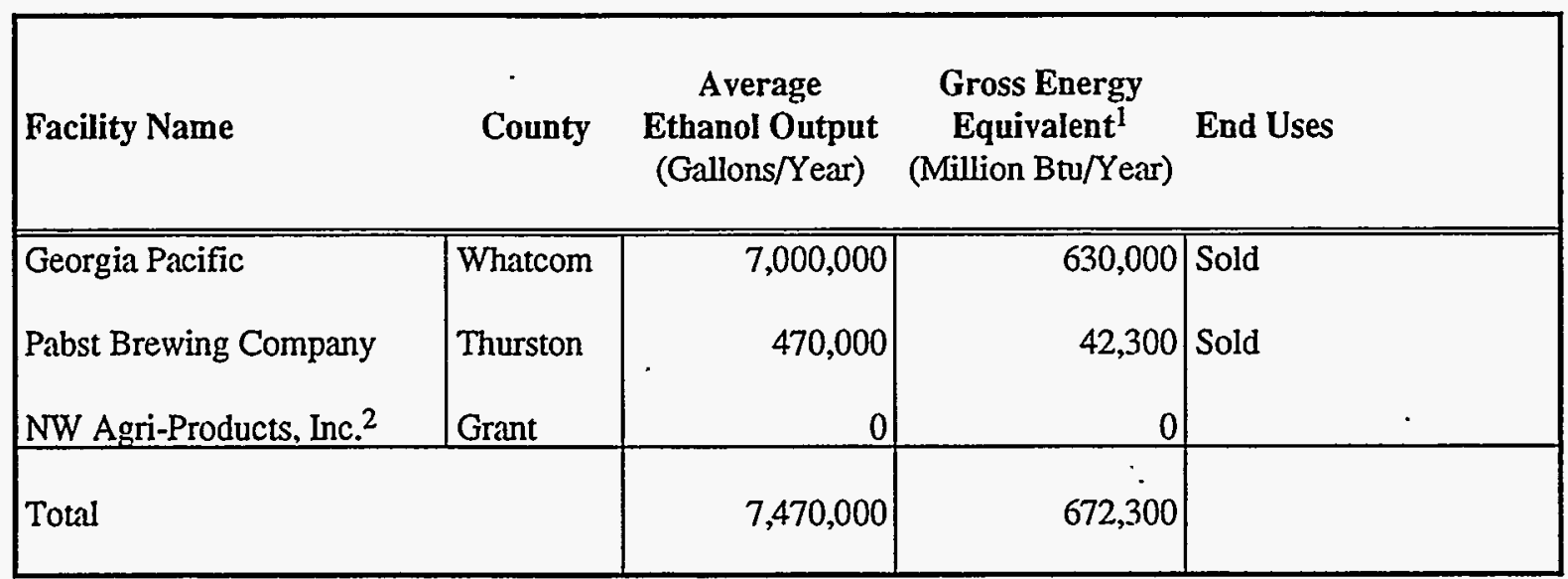

${ }^{1}$ Energy equivalent based on 90,000 Btu per gallon of ethanol.

${ }^{2}$ Facility is capable of producing 1,000,000 gallons/year, but it did not run in '93. Facility will run sometime in '94. 


\section{Ethanol Production Facilities}

\section{Georgia-Pacific Corporation}

P.O. Box 1236

Bellingham, WA 98225

Phone: (206) 733-4410

Contact: Jan Draut

Type of business: Pulp paper, chemicals

Type of feedstock: Spent pulping liquor

Source of feedstock: Plant

Plant design capacity (gallons/year):

7,000,000@190 proof

(3,000,000@ 200 proof)

Average plant output (gallons/year):

7,000,000@190 proof,

(3,000,000@200 proof)

\section{NW Agri-Products, Inc.}

716 Road NE

Moses Lake, WA 98837

Phone: (509) 762-2818

Contact: Ray Thacker

Type of business: Produce ethanol

Type of feedstock: Potatoes and grain

Source of feedstock: Local processing plants and

elevators

Plant design capacity (gallons/year):

1 million@ 200 proof

Average plant output (gallons/year): None

*Did not run in 1993 - hope to start in the spring of 1994

\section{Pabst Brewing Company}

P.O. Box 9471

Olympia, WA 9.8507

Phone: (206) 754-5010 or 754-5323

Contact: Paul Knight/Paul DeCou

Type of business: Beer

Type of feedstock: Spillage, tank wash outs

Source of feedstock: Plant

Plant design capacity (gallons/year): 1,000,000@200 proof

Average plant output (gallons/year): $470,000 @ 200$ proof 


\section{Ethanol Production Facilities Listing Changes from 1992 Edition}

Name Changes

Old

New

County

Olympia Brewing Company

Pabst Brewing Company

Thurston

No additions or deletions. 


\section{Chapter 4}

Solid Fuel Processing

Waste Wood

Wood Pellets 


\section{Waste Wood}




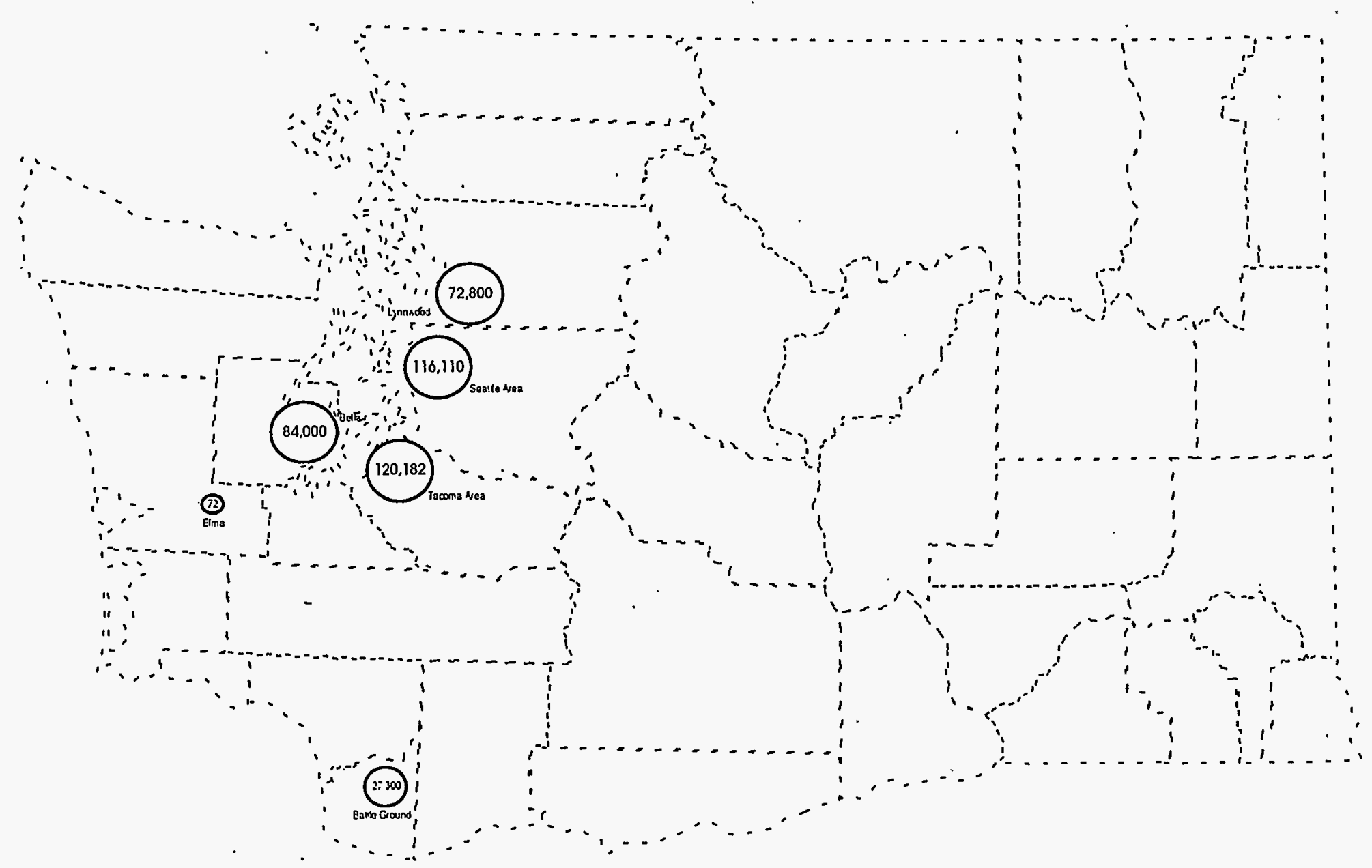

Waste wood - bone dry tons/year

\section{Figure 8}

1993 Washington State Waste Wood Processing

Source: WSEO, 1994 Washington State Directory of Biomass Energy Facilities 
Table 9

1993 Washington State Waste Wood Processing

Facilities Sorted by Average Plant Output

\begin{tabular}{|c|c|c|c|c|}
\hline Faclity Name & County & $\begin{array}{l}\text { Average Plant } \\
\text { Output }{ }^{1} \\
\text { (bone dry } \\
\text { tons/year) }\end{array}$ & $\begin{array}{l}\text { Gross Energy } \\
\text { Equivalent }^{2} \\
\text { (million } \\
\text { Btu/year) }\end{array}$ & End Uses \\
\hline $\begin{array}{l}\text { Recovery 1, Inc. } \\
\text { N. Mason Fiber Co. } \\
\text { Horizon Wood Recycling } \\
\text { D4 Care } \\
\text { Redmoor Resource Reduction } \\
\text { H\&H Wood Recyclers, Inc. } \\
\text { Cedar Grove } \\
\text { Rainier Wood Recyclers } \\
\text { Frontier Shavings } \\
\text { EGH Recycling } \\
\text { Lloyd Enterprises } \\
\end{array}$ & \begin{tabular}{|l|} 
Pierce \\
Mason \\
King \\
Snohomish \\
King \\
Clark \\
King \\
King \\
Pierce \\
Grays Harbor \\
King \\
\end{tabular} & $\begin{array}{r}120,000 \\
84,000 \\
78,000 \\
72,800 \\
27,600 \\
27,300 \\
10,000 \\
480 \\
182 \\
72 \\
30 \\
\end{array}$ & $\begin{array}{r}2,040,000 \\
1,428,000 \\
1,326,000 \\
1,237,600 \\
469,200 \\
464,100 \\
170,000 \\
8,160 \\
3,094 \\
1,224 \\
510 \\
\end{array}$ & \begin{tabular}{|l|} 
Hog fuel \\
Hog fuel \\
Hog fuel \\
Hog fuel \\
Hog fuel \\
Hog fuel \\
Hog fuel \\
Hog fuel \\
Hog fuel \\
Hog fuel, fire wood \\
Hog fuel \\
\end{tabular} \\
\hline Total & & 420,464 & $7,147,888$ & \\
\hline
\end{tabular}

1 Includes all end uses (e.g. hog fuel, compost, mulch)

${ }^{2}$ Energy equivalent based on 17 million Btu per ton of waste wood

Note: Unless otherwise given, assumed 5 day work week when quantities provided on a per day basis. 


\section{Waste Wood Facilities}

\section{Cedar Grove}

54 South Dawson

Seattle, WA 98134

Phone: (206) 764-1236

Contact: Jan Ellen

Business: Process wood waste for hog fuel

Type of feedstock: Land clearing debris, brush, pallets crating, construction waste

Source of feedstock: 50 mile radius

Plant design capacity: 10,000 tons per year

Average plant output: 10,000 tons per year

Type of products: Hog fuel

Product storage capacity: 100,000 tons

\section{D4 Care Construction Recycling Enterprises} 3900 180th Place SW

Linwood, WA 98037

Phone: (206) 774-3740

Contact: Doug Irwin

Business: Process wood waste for hog fuel

Type of feedstock: Brush, clean construction debris, pallets

Source of feedstock: Mobile (U.S. \& Canada)

Plant design capacity: 169 tons per hour

Average plant output: 104,000 green tons/year

Type of products: Hog fuel

Product storage capacity: 50,000 tons

\section{EGH Recycling}

P.O. Box 757

Elma, WA 98541

Phone: (206) 482-4651

Contact: Richard Idohl or Jerry Goodwin

Business: Process wood waste for hog fuel

Type of feedstock: Clean unpainted wood and pallet stock mill waste

Source of feedstock: Local mills

Plant design capacity: 12 tons per month (currently, expected to increase)

Average plant output: $5-7$ dry tons per month

Type of products: Hog fiel, pallet stock, firewood, pallet feed

Product storage capacity: 30 - 45 yards in-house
Frontier Shavings, Inc

20410 70th St E. (mailing address)

Bonneylake, WA 98390

Levee Rd. N. (location)

Puyallup, WA

Phone: (206) 922-0376

Contact: Mike Johnson

Business: Process wood waste for hợ fuel

Type of feedstock: Clean wood debris, stumps \& brush Source of feedstock: $50-70$ mile radius

Plant design capacity: $10,000-15,000$ yards grind

Average plant output: 500 yards

Type of products: Hog fuel

Product storage capacity: $10,000-15,000$ yards

\section{H \& H Wood Recyclers, Inc.}

P.O. Box 1855

Battle Ground, WA 98604

Phone: (206) 892-2805

Contact: Richard Henker

Business: Process wood waste for hog fuel

Type of feedstock: Dry wood products, untreated wood Source of feedstock: General Public \& construction contractors

Plant design capacity: 75 to 100 dry units per day

Average plant output: 75 to 100 dry units per day

Type of products: Hog fuel

Product storage capacity: Unlimited

\section{Horizon Wood Recycling, Inc.}

P.O. Box 1093

Woodinville, WA 98076

Phone: (206) 827-8761

Contact: Chris Nicholls

Business: Process wood waste for hog fuel

Type of feedstock: Clean wood, construction

debris, pallets

Source of feedstock: Local

Plant design capacity: 500 tons per day

Average plant output: 300 tons per day

Type of products: Chips

Product storage capacity: 8,000 tons 


\section{Lloyd Enterprises}

P.O. Box 3889

Federal Way, WA 98063

Contact: Gary Cooper

Phone: (206) 874-6692

Business: Process wood waste for hog fuel Type of feedstock: Stumps, brush, yard waste

Source of feedstock: Mobile, and 50 mile radius

Plant design capacity: Unlimited

Average plant output: 15,000 yards per year

Type of products: Hog fuel, compost

Product storage capacity: Unlimited, 143 acres

\section{North Mason Fiber Co.}

Belfair Area Urban

and Commercial Waste

431 NE Log Yard Road

Belfair, WA 98528

Contact: Bob Dressel

Phone: (206) 275-0228

Business: Process wood waste for hog fuel

Type of feedstock: Clean wood debris only. Land

clearing and wood waste

Source of feedstock: Western Washington

Plant design capacity: 600 tons per day

Average plant output: 120,000 tons annually

Type of products: Hog fuel and pulp and paper chips

Product storage capacity: Everything is hauled, 5 acres of storage

\section{Rainier Wood Recyclers}

27529 Covington Way SE

Kent, WA 98042

Contact: Tony Bennett

Phone: (206) 630-3565

Business: Process wood waste for hog fuel

Type of feedstock: Brush and stumps, clean industrial wood waste

Source of feedstock: Local businesses, on-site grinders

Plant design capacity: 40,000 yards mo.

Average plant output: 20,000 yards mo.

Type of products: Hog fuel, screened hog fuel

Product storage capacity: 40,000 yards
Recovery 1, Inc.

1630 E. 18th St.

Tacoma, WA 98421 .

Contact: Dave Newbauer

Phone: (206) 627-1180

Business: Process wood waste for hog fuel

Type of feedstock: Demolition debris,stumps, pallets

Source of feedstock: Contractors, land clearing, pallet rebuilding

Plant design capacity: 120,000 BDTs per year

Average plant output: 60 tons per hour

Type of products: Hog fuel, pulp chips, particle board

Product storage capacity: 2,5000 yards raw, 2,500 yards

processed

\section{Redmoor Resource Recovery, Inc.}

P.O. Box 3545

Redmond, WA 98073

Contact: Steve McFall

Phone: (206) 885-9416

Business: Process wood waste for hog fuel

Type of feedstock: $70 \%$ used lumber, pallets, crates $30 \%$

stumps

Source of feedstock: Local businesses and contractors

Plant design capacity: 72,000 tons per year

Average plant output: 27,600 tons per year

Type of products: Boiler Fuel

Product storage capacity: Manufacture what is ordered. 


\section{Waste Wood Processing Facilities Listing Changes from 1992 Edition}

\section{Additions}

Cedar Grove

D4. Care

Frontier Shavings

Lloyd Enterprises

North Mason Fiber Co.

Recovery 1, Inc.

\section{Deletions}

McHugh Recycling

Northwest Wood Recycling

Portside Recycling

Waste Reduction, Inc.
Cause

Went out of business.

See, Rainier Wood Recyclers

Out of business

Out of business
County

King

Snohomish

King":

King

Mason

Pierce

\section{County}

Thurston

King

Pierce

Thuston

\section{Name Changes}

Old

Horizon Trucking \& Excavation, Inc. $\underline{\text { New }}$

Horizon Wood Recycling

\section{County}

King 


\section{Wood Pellets}




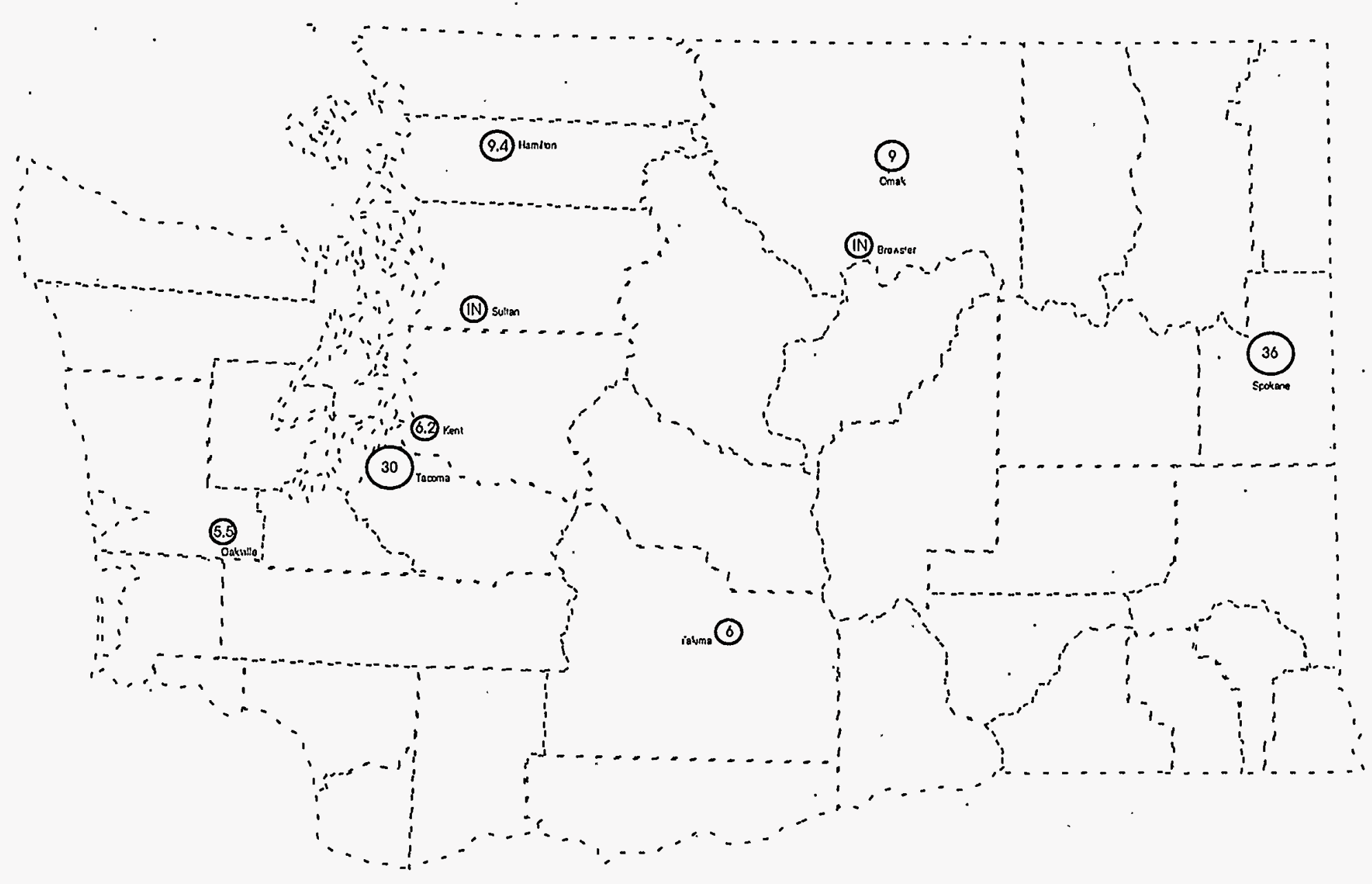

Wood pellets- bone dry tons/year

Figure 9

1993 Washington State Wood Pellet Processing

Source: WSEO, 1994 Washington State Directory of Biomass Energy Facilities

IN - Inactive 
Table 10

1993 Wood Pellet Processing

Sorted by Average Plant Output

\begin{tabular}{|c|c|c|c|c|}
\hline Facility Name & County & $\begin{array}{c}\text { Average } \\
\text { Plant,Output } \\
\text { (BDT/Yr) }\end{array}$ & $\begin{array}{l}\text { Gross Energy } \\
\text { Equivalent } \\
\text { (Million Btu) }\end{array}$ & End Uses \\
\hline $\begin{array}{l}\text { Spokane Pres-To-Logs } \\
\text { Manke Lumber Company } \\
\text { Kaaland Mill } \\
\text { CD Pellet Company } \\
\text { Seattle-Tacoma Box Co. } \\
\text { Simmons Densified Fuels } \\
\text { Wood Pellet Company } \\
\text { Johnson Pellet Mills, Inc. } \\
\text { MMM Pellet Mills } \\
\end{array}$ & $\begin{array}{l}\text { Spokane } \\
\text { Pierce } \\
\text { Skagit } \\
\text { Okanogan } \\
\text { King } \\
\text { Yakima } \\
\text { Grays Harbor } \\
\text { Snohomish } \\
\text { Okanogan } \\
\end{array}$ & $\begin{array}{r}36,000 \\
30,000 \\
9,360 \\
9,000 \\
6,200 \\
6,000 \\
5,475 \\
\text { inactive } \\
\text { inactive } \\
\end{array}$ & $\begin{array}{r}612,000 \\
510,000 \\
159,120 \\
153,000 \\
105,400 \\
102,000 \\
93,075 \\
\text { inactive } \\
\text { inactive } \\
\end{array}$ & $\begin{array}{l}1 / 4^{\prime \prime} \text { Diameter wood pellets, } 8 \# \text { logs } \\
\text { Wood pellets } \\
\text { Wood pellets } \\
\text { Wood pellets } \\
\text { Wood pellets } \\
1 / 4^{\prime \prime} \text { Diameter wood pellets } \\
1 / 4^{\prime \prime} \text { Diameter wood pellets } \\
1 / 4^{\prime \prime} \text { Diameter wood pellets } \\
\text { Wood pellets, kitty litter } \\
\end{array}$ \\
\hline Total & & 102,035 & $1,734,595$ & \\
\hline
\end{tabular}

IEnergy equivalent based on 17 million Btu per ton of wood pellets 


\section{Wood Pellets}

\section{Pellet Company}

P. O. Box 3185

Omak, WA 98841

Phone: (509) 826- 2059

Contact: Cherie Moomaw

Type of Feedstock: Planner shavings

Source of Feedstock: Local mill

Plant Design Capacity: 9,000 tons per year

Average Plant Output: 9,000 tons per year

Type of Products: Wood pellets

Product Storage Capacity: 3,000 tons

\section{Johnson Pellet Mills, Inc.}

P.O. Box 41

Sultan, WA 98294

Phone: (206) 793-3133

Contact: Stan Johnson, Sr.

Type of Feedstock: Fir and Hemlock

Source of Feedstock:

Plant Design Capacity: 14,000

Average Plant Output:

Type of Products: $1 / 4^{\text {" wood pellets }}$

Product Storage Capacity: 600 tons

*Note: Plant is inactive, plans to reopen in near future.

\section{Kaaland Mill}

P.O. Box 533

Hamilton, WA 98255

Phone: (206) 826-4344

\section{Contact: Don Kaaland}

Type of Feedstock: Fir \& cedar shavings and sawdust Source of Feedstock: In-house, purchase Plant Design Capacity: 60 tons per day Average plant output: 60 tons per day, 3 days/week Type of Products: Wood pellets

Product Storage Capacity: 500 tons

\section{MJM Pellet Mill}

Rt. 1 Box 104

Brewster, WA 98812

Phone: (509) 689-3188

Contact: Mathew Michaels

Type of Feedstock: Planner shavings

Source of Feedstock: No source of feedstock

Plant Design Capacity: 20 tons per day

Average Plant Output:

Type of Products: Wood pellets, kitty litter

Product Storage Capacity: 100 tons

*Note: Plant is not operating at this time due to lack of feedstock.

\section{Manke Lumber Company}

1717 Marine View Drive

Tacoma, Washington 98422

Phone: (206) 572-6252

Contact: Milton Farvour

Type of Feedstock: Sawdust and Shavings

Source of Feedstock: Local mills

Plant Design Capacity: 240 tons/day x 312 days/year = 74,880 tons/year

Average Plant Output: 10 tons/hr @ 20 hrs x 200 day per $\mathrm{yr}=30,000$ tons/yr.

Type of Products: Pellets

Product Storage Capacity: 7,500 tons 
Seattle-Tacoma Box Co.

2340071 st Place S.

Kent, WA 98032

Phone: (206) 854-9700

Contact: Tom Nist

Type of Feedstock: Fir, Spruce, Pine Source of Feedstock: In-house \& purchased Plant Design Capacity: 7,000 tons/yr Average Plant Output: 6,200 tons/yr Type of Products: Premium Wood Pellets Product Storage Capacity: 2,500 tons

Simmons Densified Fuels, Inc. 2318 S. First

Yakima, WA 98903

Phone: (509) 453-6008

Contact: Dave or Ron Simmons

Type of Feedstock: Dry sawdust \& shavings Source of Feedstock: Local cutstock plants

Plant Design Capacity: 84 tons/day, 30,000 tons/yr

Average Plant Output: 30 tons/day, 6,000 tons/yr

Type of Products: 1/4" diameter wood pellets Product Storage Capacity: 1,000 tons

\section{Spokane Pres-To-Logs}

\section{P.O. Box 787}

Otis Orchards, WA 99027

Phone: (509) 924-2807

Contact: Dave Armstrong

Type of Feedstock: Dry Planner Shavings Source of Feedstock: Local mills

Plant Design Capacity: 20,000 tons/yr pellets, 20,000 tons/yr logs

Average Plant Output: 18,000 tons/yr pellets, 18,000 ton/yr logs

Type of Products: $1 / 4$ " diameter 1 " long pellets (bulk and bags) $8 \#$ logs

Product Storage Capacity: 4,000 tons
Wood Pellet Company

P.O. Box 307

Oakville, WA 98568

Phone: (206) 273-6982 .

Contact: Dick Rathvon

Type of Feedstock: Mill shavings and sawdust Source of Feedstock: Local mills Plant Design Capacity: 24 tons per day Average Plant Output: 15 tons per day Type of Products: 1/4" pellets, bagged Product Storage Capacity: 200 tons 


\section{Wood Pellet Processing Facilities Listing Changes from 1992 Edition}

Deletions

Panorama Wood Products

Pope and Talbot, Inc.
Cause

No longer producing pellets.

Out of business.
Countr

Stevens

Kitsap... . 


\section{Conversion Table}




\section{Conversion Table}

Multiply

Bone Dry Ton

Bone Dry Unit

Green Ton

One Gallon Ethano!

One Pound Bone Dry Hog Fuel

One Pound MSW

One ton

Unit
By

1.1023

1.2

( 1 - moisture content)

84,610

8,500

5,000

2,000

1.1
To Obtain

bone dry ton

bone dry ton

bone dry ton

Btu

Btu

Btu

Pounds

Bone Dry Tons 


\section{Table of Abbreviations}




\title{
Table of Abbreviations
}

\author{
BDMT - bone dry metric ton \\ BDT - bone dry ton \\ BDTs - bone dry tons \\ BDT/yr - bone dry ton per year \\ BDU - bone dry unit \\ bhp - boiler horse power \\ Btu - British thermal unit \\ hp - horse power \\ kW - kilowatt \\ kWh - kilowatt-hour \\ Ib/hr - pound per hour \\ Ibs/hr - pounds per hour \\ MGD - million gallons per day \\ MSW - municipal solid waste \\ MW - electric capacity, megawatts \\ MWh - electric production, megawatt-hour \\ psi - pounds per square inch \\ psig - pounds per square inch, guage \\ RDF - refuse derived fuel \\ scf - standard cubic feet \\ STP - sewage treatment plant \\ WWTF - waste water treatment facility
}




\section{Glossary}




\section{GLOSSARY*}

Anaerobic: Pertaining to the absence of free oxygen.

Anaerobic digestion: A biochemical degradation process that converts complex organic materials to methane and other by-products.

Bioenergy: The conversion of the complex carbohydrates in organic matter into energy, either by using it directly as a fuel or by processing it into liquids and gases that are more efficient.

Biogas: A combustible gas derived from decomposing biological waste.

Biomass: Any organic matter which is available to be used as a fuel on a renewable basis including forest residues, agricultural crops and wastes, wood and wood wastes, animal wastes, livestock operation residue, aquatic plants, and municipal wastes.

Biomass fuel: Any liquid, solid, or gaseous fuel produced by conversion from biomass.

Boiler horsepower: An arbitrary unit in the English system of measure for the equivalent of 33,480 Btu gross output or evaporation of 34.5 pounds of water per hour at $212^{\circ} \mathrm{F}$.

Bone dry (oven dry): Having zero percent moisture content. Wood heated in an oven at a constant temperature of $212^{\circ} \mathrm{F}$. or above until its weight stabilizes.

Bone dry unit (BDU): A quantity of wood residue which weighs 2,400 pounds at zero percent moisture content.

British Thermal Unit (Btu): The amount of heat required to raise the temperature of one pound of water one degree Fahrenheit.

Capacity: The maximum instantaneous output of a resource, often expressed in kilowatts or megawatts.

Chips: Woody material cut into short, thin wafers, used as a raw material for pulping, fiberboard, or for energy use.

Chip vans: Special construction bottom dump trucks (grain trucks) or conventional tractor-trailer vans used for hauling pulp chips, mill residues, hog fuel, and other biomass of smaller piece sizes.

Cogeneration: The technology of producing electric energy and forms of useful energy (thermal or mechanical) for industrial, commercial, heating, or cooling purposes, through the sequential use of an energy source.

Combustion: A chemical process, especially oxidation, accompanied by the production of heat and light.

Cord: A stack of wood consisting of 128 cubic feet with standard dimensions of $4^{\prime} \times 4^{\prime} \times 8^{\prime}$, including air space and bark; typically 1.2 bone dry tons per cord.

Cubic Foot (CF): $12^{\prime \prime} \times 12^{\prime \prime} \times 12^{\prime \prime}$ or $1^{\prime} \times 1^{\prime} \times 1^{\prime}$.

Digester: A vessel in which carbon containing biomass is reacted in water in absence of air to produce biogas. 
Dry ton: 2,000 pounds of material dried to a constant weight.

Dutch oven furmace: One of the earliest types of furnaces that is a large, rectangular box, lined on the sides and top with fire brick (refractory) that is commonly used for wood firing. Heat is stored in the refractory and radiated to the conical fuel pile in the center of the furnace.

Ethanol: Ethyl alcohol produced by fermentation and distillation.

Feedstock: Any material which is converted to another form or product.

Fly ash: Small ash particles carried in suspension in combustion gases.

Forest residues: Wasted and unutilized wood in the forest, including logging residue, rough, rotten, and dead trees, and annual mortality.

Fossil fuel: A solid, liquid, or gaseous fuel material formed in the ground by chemical and physical changes in plant and animal residues under high temperature and pressure.

Fuel-cell furnace: A variation of the Dutch oven design, that usually incorporates a primary and secondary combustion chamber. The primary is a vertical refractory-lined cylinder with a grate at the bottom in which combustion is partially completed. Combustion is completed in the secondary cell.

Fuel handling system: The delivered wood fuel is unloaded from vans or trucks and transported to a storage pile or bin. From storage, the wood fuel is conveyed mechanically or pneumatically to the energy conversion system.

Gasification: A chemical or heat process used to convert a feedstock to a gaseous form.

Gasifier: A device for converting solid fuel into gaseous fuel. In biomass systems, the process is referred to as pyrolytic distillation. See pyrolysis.

Green ton: 2,000 pounds of undried material, e.g., wood residue including moisture content.

Hogged (hog) fuel: Wood waste such as sawdust, planer shavings, and wood chunks normally used for fuel purposes.

Horsepower: Electrical: A measure of time rate of mechanical energy output. The term is usually applied to electric motors to describe maximum output. 1 electrical horsepower $=0.746$ kilowatts $=2,545$ British thermal units per hour. Also see Boiler Horsepower.

Kilowatt: 1,000 watts, a measure of electrical power.

Logging residues: The unused portions of saw timber and pole timber trees cut or dilled during the harvesting process.

Megawatt (MW): An electrical generation unit of one million watts or 1,000 kilowatts.

Methane: An odorless, colorless, flammable gas that is the primary constituent of natural gas.

MGD: Million gallons per day. 
Mill residue: Wood and bark residues produced in processing lumber.

Moisture content, dry basis (MCDB): Expressed as a percentage of the weight of the oven-dry wood. $\mathrm{MCWB}=$ (weight wet sample-weight dry sample) weight dry sample $\mathrm{x} 100$

Moisture content, wet basis (MCWB): Expressed as a percentage of the weight of the wood as received. (weight wet sample-weight dry sample) weight wet sample $\times 100$

Moisture content (MC): The moisture content is the amount of water contained in the fuel.

Oven dry: See bone dry.

Oven dry ton (ODT): An amount of wood that weighs 2,000 pounds at zero percent moisture content.

Pounds: Pound mass $=$ A unit of mass equal to 0.454 kilograms.

Pound of steam: One pound mass of water converted to steam.

Power conversion factors (rate of flow of energy): Watts $=3.413$ British thermal units per hour; kilowatts $=$ 1,000 watts $=1.341$ horsepower $=3,413$ British thermal units per hour; horsepower $=745.7$ watts, etc.

Psi: Pounds of pressure per square inch.

Psig: Pounds/force per square inch gauge.

Pyrolysis: A process of burning at less than stoichiometric conditions involving the physical and chemical decomposition of solid organic matter by action of heat in the absence of oxygen.

RDF: Refuse-derived fuel; the combustible portion of solid waste that has been processed to remove heavier, noncombustible materials.

Renewable energy resource: Any energy resource which has recently originated in the sun, including direct and indirect solar radiation and intermediate solar energy forms such as wind, ocean thermal gradients, ocean currents and waves, hydropower, photovoltaic energy products of photosynthetic processes, organic wastes, and others.

Saturated steam: Steam at the temperature which corresponds to its boiling temperature at the pressure.

SCF: Standard cubic foot.

SCFM: Standard cubic foot per minute.

Scrubber: A device in which combustible or stack gas is cleaned by the spraying of water.

Spreader stoker furnace: Fuel is automatically or mechanically spread across the fumace. A portion is suspension burned, but large pieces fall on a grate.

Steam Turbine: A device for converting energy of high-pressure steam (produced in a boiler) into mechanical power which can then be used to generate electricity. 
Turbine: A machine for converting heat energy in steam or high temperature gas into mechanical energy as the high velocity flow of steam or gases passes through successive rows of radial blades fastened to a central shaft.

Unit: 200 cubic feet, bulk measure, used to measure hog fuel, pulp chips, etc. Contains varying amounts of solid material depending on the amount of compaction. It is now more customary to weigh material, correct for moisture, and calculate the number of bone dry tons.

Watt: The common base unit of power in the metric system. 1 kilowatt $=1,000$ watts; $1 \mathrm{kWh}$ (kilowatt hour) $=$ the amount of power consumed for one hour. 1 megawatt $=1,000,000$ watts.

*Excerpted from: Pacific Northwest and Alaska Bioenergy Program Glossary (1985), and the Department of Energy Biomass Energy Project Development Guidebook. 


\section{INDEX}

Aberdeen Landfill $\quad 3,4$

Allen Logging Company $\mathbf{3 5 , 3 7}$

Boise Cascade Corporation - Kettle Falls 35, 37, 38

Boise Cascade Corporation - Steilacoom 35, 38

Boise Cascade Corporation - Wallula 35, 38

Boise Cascade Corporation - Yakima 35, 39

Bremerton Wastewater Treatment Plant, City of 11,12

Buffelen Woodworking 35, 39

Cathcart Landfill 3,4

Cedar Grove $65,66,68$

Cedar Hills Landfill 3,4

Cedarville Landfill 3,4

Central Kitsap Treatment Plant $\mathbf{1 1 , 1 2}$

Centralia Landfill 3,4

Centralia Wastewater Treatment Plant, City of 11, 12

CD Pellet Company $\mathbf{7 1 , 7 2}$

Chambers Creek Treatment Plant 11, 12

Chehalis Wastewater Treatment Plant, City of $\mathbf{1 1 , 1 2}$

Chelan Treatment Plant 11, 13

Coastcraft (Kroon, Inc.), Incorporated 36, 39, 56

College Place Wastewater Treatment Facility 11, 13, 19

Colville Indian Precision Pine Company 35, 40

Cowlitz Co. Landfill 3,5

Cowlitz Stud Company 35,40

Crown-Pacific Inland $\mathbf{5 2 , 5 6}$

D4 Care 65, 66, 68

Daishowa America 35, 40

Dayton Wastewater Treatment Plant, City of 11, 13

DeGoede Bulb Farms 36, 54

Des Moines Creek Treatment Plant 11, 13

Douglas County Sewer District 11, 13

E.G.H. Recycling 65,66

Ellensburg Wastewater Treatment.Plant, City of 11, 13

Enumclaw Landfill 3,5

Fort Vancouver Plywood 35, 41

Fred Tebb \& Sons, Incorporated 36,41

Frontier Shavings 65, 66, 68

GN Plywood 35, 42, 56

Georgia-Pacific Corporation 35, 41, 59, 60

Goodyear-Nelson Hardwood Lumber Company, Incorporated 35, 42

Guy Bennet Lumber Co. 35, 42

H \& H Wood Recyclers, Inc. 65,66

Hansville 3,5

Hardel Mutual Plywood 35, 43

Hawks Prarie Landfill 3,5

Hidden Valley Landfill 3,5

Hobart Landfill 3,6 
Hoquiam Landfill 3,6

Horizon Trucking and Excavation, Inc. 68

Horizon Wood Recycling, Inc. 65, 66, 68

ITT Rayonier 56

James River 23, 24, 35, 43

Jeld-Wen Fiber of Washington 35,44

Jeld-Wen of Washington 35, 43

Johnson Pellet Mills, Inc. 71, 72

K-Ply, Inc. 35, 44

Kaaland Mill 71, 72

Kent Highlands Landfill 3, 6

Kinnear of Washington 36, 44

Kroon, Inc (Coastcraft, Inc.) .36, 39, 56

Lacey, Olympia, Tumwater, Thurston County (LOTT) 11, 14

Layman's Lumber Company $\mathbf{3 6 , 4 5}$

Leichener Landfill 3,6

Lloyd Enterprises 65, 67, 68

Longview Fibre Company 23, 24

Louisiana Pacific Company 36,45

MJM Pellet Mill 71, 72

McCleary Sewage Treatment Facility 19

McHugh Recycling 68

Manke Lumber Company $\mathbf{7 1 , 7 2}$

Mason Co. Landfill 3,6

Metro Alki Treatment Plant 11, 14

Metro West Point Treatment Plant 11, 14

Midway Landfill 3,7

Miller Creek Sewage Treatment Plant 11, 14

Morton Forest Products 35, 46

Mount Vernon Sewer Department, City of 11,14

Mt. Baker Plywood 56

NW Agri-Products 59, 60

Newport Wastewater Treatment Plant, City of 11,14

North Mason Fiber Co. 65, 67, 68

Northwest Wood Recycling 68

Northwest Hardwoods 35, 46

Oak Harbor Wastewater Treatment Plant, City of 11,15

Oeser Company, The 35, 46

Olympia Brewing Company 61

Olympic View Sanitary Landfill 3,7

Omak Wood Products, Incorporated 35, 47

Pabst Brewing Company $\mathbf{5 9 , 6 0 , 6 1}$

Pacific Wood Treating 56

Panorama Wood Products 74

Pasco Sewage Treatment Plant, City of $\mathbf{1 1 , 1 5}$

Plum Creek Manufacturing, Incorporated 35, 47

Pope \& Talbott, Inc. 74

Port Angeles Wastewater Treatment Plant, City of 11, 15

Port Orchard/Kitsap County Sewer District \#5 11, 15 
Port Townsend Paper 35, 47

Portside Recycling 68

Prosser Wastewater Treatment Facilities, City of 11, 15

Puget Sound Plywood 56

Pullman Wastewater Treatment Plant 11,15

Purdy Landfill 3,7

Puyallup Pollution Control Facility (wastewater treatment facility) 11, 16

Rainier State School Sewage Treatment Plant 11, 16

Rainier Wood Recyclers 65, 67

Rayonier, Inc. 35, 48, 56

Recomp of Washington 29, 30

Recovery 1 , Inc. $65,67,68$

Redmoor Resource Reduction 65, 67

Redondo Wastewater Treatment Plant 11, 16

Renton Treatment Plant 11, 16

Richland Wastewater Treatment Plant 11, 16

Roosevelt Regional Landfill $\quad 3,7$

Salmon Creek Sewage Treatment Plant 11, 16

San Poil Lumber Company 56

Seattle-Tacoma Box Co. 71, 73

Scott Paper 35, 48

Shelton Corrections Center 35, 54

Simmons Densified Fuels, Inc. 71, 73

Simpson Door Company 35, 48

Simpson Tacoma Kraft Company 35, 49

Simpson Timber Company 35,49

Skagit County Resource Recovery Facility 29, 30

Smith Street Mill, Inc. 36, 49

Southwest Suburban Sewer District 14, 16

Spokane Pres-To-Logs 71, 73

Spokane Trash-to-Energy Facility 29, 30

Spokane Wastewater Treatment Plant 11, 17

Stevenson Co-Ply, Inc. 56

Strauser Manufacturing Company $\mathbf{3 6 , 5 0}$

Summit Timber Power House $\mathbf{3 5 , 5 0}$

Sunnyside Wastewater Treatment Plant 11, 17

Tacoma Landfill 3,7

Tacoma Sewage Treatment Plant-1, City of 11,17

Tacoma Sewage Treatment Plant-3, City of 11, 17

Tacoma Steam Plant \#2 29, 30, 35, 50

Toppenish Wastewater Treatment Plant 11, 17

Vaagen Brothers Lumber, Incorporated - Colville 35, 51

Vaagen Brothers Lumber, Incorporated - Ione 35, 51

Vaagen Brothers Lumber, Incorporated - Republic 35, 51, 56

W.I. Forest Products - Spokane 35, 52, 56

Walla Walla Wastewater Treatment Plant 11,17

Washington Soldiers Home \& Colony 36, 54

Washington State Penitentiary $\mathbf{3 6 , 5 5}$

Washington Water Power Company 35, 55 
Waste Reduction, Inc. 68

Wenatchee Water Pollution Control Plant 11, 18

West Coast Forest Products, Incorporated 36, 52

Westem State Hospital 36,55

Weyerhaeuser Company - Cosmopolis 35,52

Weyerhaeuser Company-Longview $35 ; 53$

Weyerhaeuser Company - Raymond 35, 53

Weyerhaeuser Company - Snoqualmie Falls 35, 53

Wood Pellet Company $\mathbf{7 1 , 7 3}$ 